\title{
TERTIARY TEACHERS' MOTIVATION FOR CHOOSING AND REMAINING IN TEACHING IN A PUBLIC UNIVERSITY IN CAMBODIA
}

\author{
By
}

Dinath Kim

A four-paper thesis submitted in partial fulfillment of the requirements for the degree of Master of Education

Victoria University of Wellington

2013 


\begin{abstract}
The motivation of tertiary teachers in Cambodian higher education has not received much attention over the years. Specifically, very little is known about factors that motivate and demotivate Cambodian tertiary teachers in choosing and remaining in their teaching careers. The purpose of the study is to investigate: 1) the factors which influenced teachers to choose teaching careers, 2) motivating and de-motivating factors associated with their teaching, and 3) motivations which may lead them to leave or stay in their teaching careers. It is important to examine the motivational factors that are influential for Cambodian university teachers in order to increase their teaching productivity so that the institutional effectiveness can be enhanced which will lead to improvement in the quality of Cambodia higher education. This research used a single exploratory case study within a qualitative methodology. The study was conducted at two departments in a typical public university in Cambodia. The data was collected through the implementation of one questionnaire that attracted 36 respondents and one semi-structured interview held with each of 8 volunteer participants. Thematic analysis was used to analyse interview data and open-ended questionnaire data. The findings of the study reveal that intrinsic factors were more important than extrinsic factors in influencing teacher motivation in becoming and remaining in teaching. However, extrinsic factors were de-motivating teachers in their teaching and may lead them to leave the profession. The findings are discussed in the context of some theories of motivation and previous empirical studies. Recommendations are made regarding strategies to be used and what further research can be undertaken to address the problem.
\end{abstract}




\section{ACKNOWLEDGEMENT}

There are a number of people I would like to acknowledge and thank for their support, guidance, encouragement, and love.

I would like to express my heartfelt thanks and appreciation to my supervisor, Dr. Dayle Anderson, for your continuous encouragement, wisdom, patience, constructive academic guidance, and excellent supervision throughout this journey. Without your support, this thesis could not have been successfully completed.

I would like to thank New Zealand's International Aid \& Agency Development (NZAid) for awarded me the scholarship and NZAid's staff who provided great care and assistance from the beginning to the end of my study. I express my sincere gratitude to VUW's staff and especially librarians for their tremendous help.

I am truly indebted to Rector of the University who allowed me to conduct the study at his university. I also would like to express my deepest thanks to the participants for their time, willingness to share their thoughts, and contribution in my thesis. My profound thanks also go to my all friends for their constant support and encouragement.

My special gratefulness is extended to my beloved parents, Kolyuthy Kim and Dina Van, and my brother for their continuous support, encouragement, patience, and love. In particular I would like to thank my husband Seiyuth Ban for your patience, understanding, and support in so many ways which made it possible for me to complete my study. 
Abstract

Acknowledgements

Table of Contents

List of tables and figures

\section{CHAPTER 1 INTRODUCTION}

1.1 Context of the study

1.2 The research problem

1.3 Purpose of the Study

1.4 Significance of the study

1.5 Researcher background

1.6 Organisation of the thesis

\section{CHAPTER 2 LITERATURE REVIEW}

2.1 Motivation

2.2 De-motivation

2.3 Intrinsic and extrinsic motivation

2.3.1 Intrinsic motivation

2.3.2 Extrinsic motivation

2.4 Theories of motivation

2.4.1 Content theories

2.4.1.1 Maslow's hierarchy of needs

2.4.1.2 Herzberg's two-factor theory

2.4.2 Process theories

2.4.2.1 Goal setting theory.

2.4.2.2 Expectancy theories

2.4.2.3 The Equity theories

2.4.3 Applicability of motivation theories to the study

2.5 Teacher motivation

2.6 Teacher motivation in higher education

2.7 Teacher motivation in Cambodia 


\section{CHAPTER 3 METHODOLOGY}

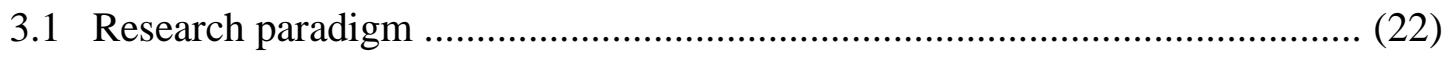

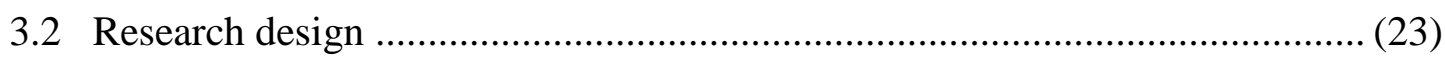

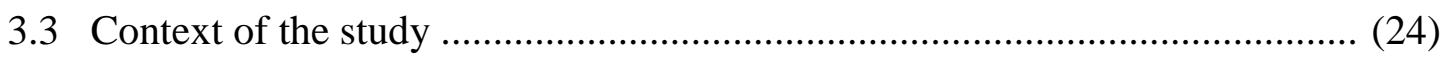

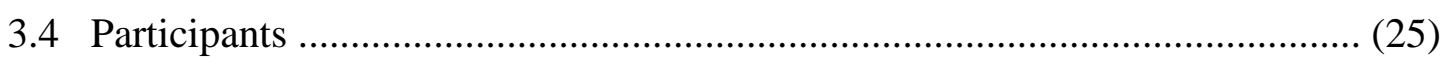

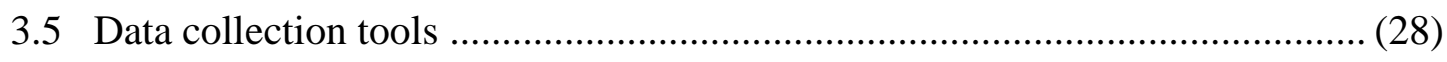

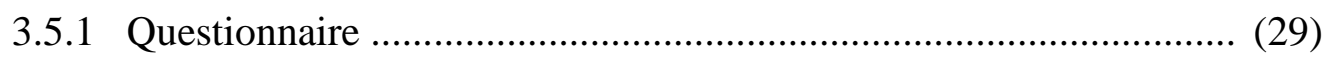

3.5.2 Semi-structured interviews .................................................... (30)

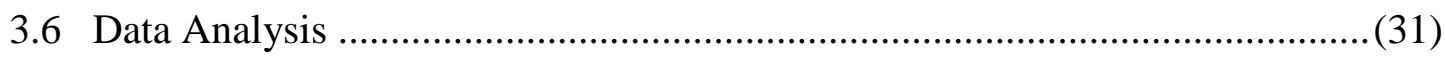

3.6.1 Analysis of interview data and open-ended questionnaire data ...... (31)

3.6.2 Likert questionnaire data .......................................................(33)

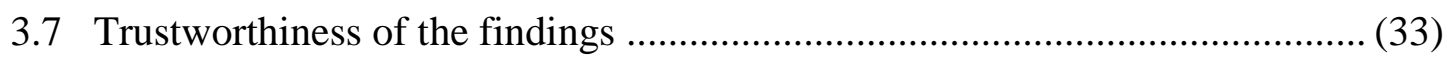

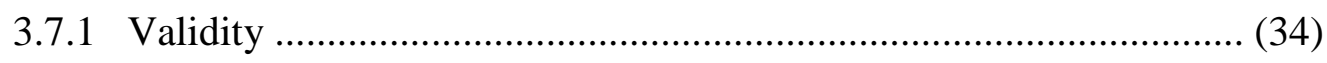

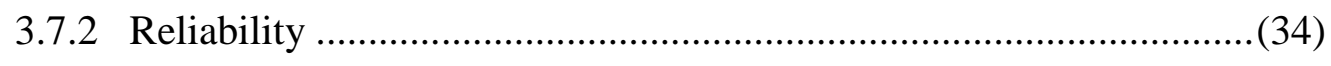

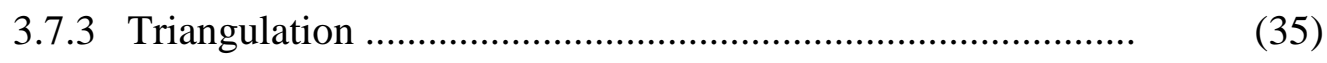

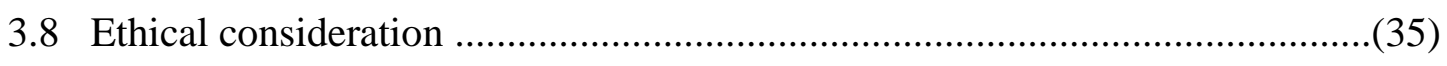

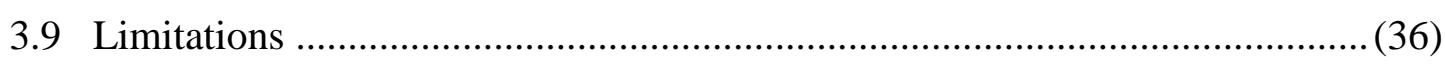

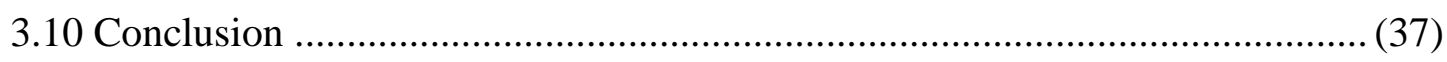

\section{CHAPTER 4 FINDINGS}

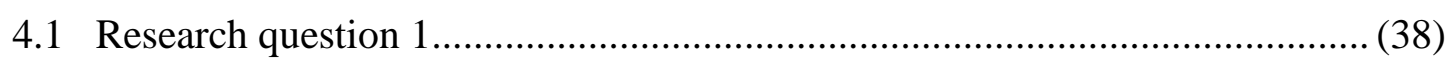

4.1.1 Helping younger generations and contributing to society ............... (38)

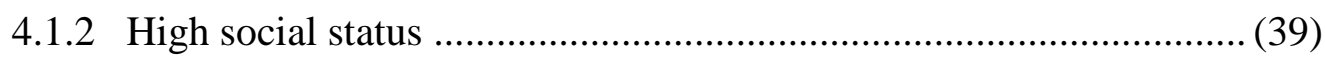

4.1.3 Personal interest in teaching .................................................... (40)

4.1.4 Upgrading knowledge and skills .................................................(40)

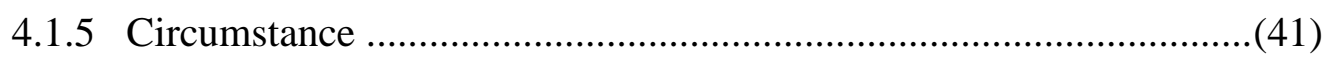

4.1.6 Salary and living standards of teachers ........................................(41)

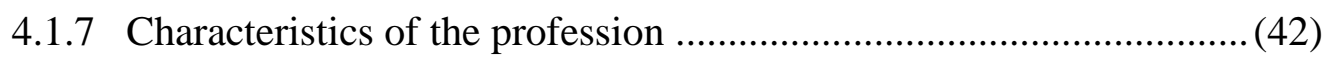

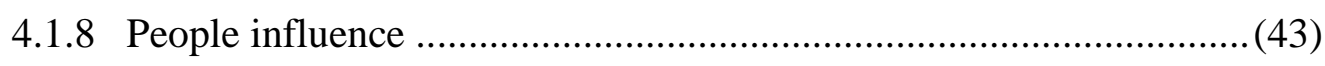

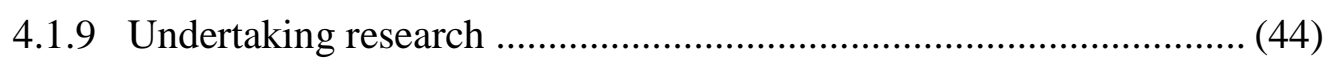

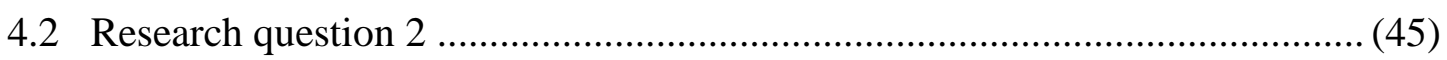

4.2.1 Current motivating factors ..................................................... (45) 
4.2.1.1 Helping younger generations and contributing to society ..(45)

4.2.1.2 Upgrading knowledge and skills

4.2.1.3 Devotion to teaching

4.2.1.4 High social status

4.2.1.5 Opportunities for further study

4.2.1.6 Characteristics of the profession

4.2.1.7 Undertaking research

4.2.2 Potential motivating factors

4.2.2.1 Physical working environment

4.2.2.2 Recognition from the university

4.2.2.3 Salary

4.2.2.4 Management support and leadership

4.2.2.5 Power

4.2.2.6 Feedback

4.2.2.7 Opportunities for undertaking research

4.2.2.8 Opportunities for upgrading knowledge and skills

4.2.2.9 Students

4.2.2.10 Cooperation within the university

4.3 Research question 3

4.3.1 Lack of physical working environment

4.3.2 Low salary

4.3.3 Lack of autonomy

4.3.4 De-motivating policy

4.3.5 Lack of management support and poor leadership

4.3.6 Lack of cooperation within the university

4.3.7 Friendship networks

4.3.8 Students' poor performance

4.3.9 Lack of recognition

4.4 Research question 4

4.4.1 Factors that may motivate the teachers to leave teaching

4.4.1.1 Low salary

4.4.1.2 Lack of physical working environment

4.4.1.3 Lack of autonomy in subject teaching

4.4.1.4 Lack of opportunities for undertaking research 
4.4.1.5 Lack of opportunities for upgrading knowledge and skills (63)

4.4.1.6 Friendship networks

4.4.1.7 Students' poor performance

4.4.1.8 Lack of management support and leadership

4.4.2 Motivations that may lead the teachers to stay in teaching

4.4.2.1 Personal interest in teaching

4.4.2.2 High social status

4.4.2.3 Upgrading knowledge and skills

4.4.2.4 Characteristics of the profession

4.4.2.5 Helping younger generations

4.5 Conclusion

\section{CHAPTER 5 DISCUSSION AND CONCLUSION}

5.1 Summary of the findings

5.2 Motivations for becoming tertiary teachers

5.2.1 Intrinsic motivation

5.2.1.1 Helping younger generations

5.2.2 Extrinsic motivation

5.3 Current tertiary teaching: Motivating and de-motivating factors

5.3.1 Intrinsic motivation

5.3.2 Extrinsic motivation

5.3.3 Potential motivating and current de-motivating factors

5.3.3.1 Salary

5.3.3.2 Physical working environment

5.3.3.3 Management support and leadership

5.3.3.4 Feedback

5.3.3.5 Friendship networks

5.3.3.6 Recognition

5.4 Future: Motivations for remaining and leaving tertiary teaching

5.5 Limitations, implications and recommendations

5.5.1 Limitations

5.5.2 Implications for future research

5.5.3 Recommendations

5.6 Reflections of the researcher 


\section{APPENDICES}

Appendix A: Letter to request for university permission

Appendix B: Questionnaire

Appendix C: Interview questions

Appendix D: Teacher information sheet

Appendix E: Teacher consent form

Appendix F: Interview participant form

Appendix G: Pilot participant information sheet

Appendix H: Pilot participant consent form

Appendix I: Transciber confidentiality agreement (106) 


\section{Tables and Figures}

Table 2.1: Motivator and Hygiene factors

Table 3.1: 36 Questionnaire participants' background information

Table 3.2: Interview participants' background information

Table 3.3: Chronological order of data collection processes

Figure 1: Summary of the findings 


\section{CHAPTER 1}

\section{Introduction}

This chapter sets the scene for this study on the motivations of Cambodian tertiary teachers; the factors which influence them to take up teaching, support them and prevent them from teaching well, and lead them to leave or remain in their teaching. It introduces the context of the study, the research problem, the significance of the study, research questions, researcher background, and an overview of the thesis.

\subsection{Context of the study}

The Kingdom of Cambodia is located in Southeast Asia with a total landmass of 181,035 square kilometres and bordered by Thailand to the northwest, Laos to the northeast, and Vietnam to the east. The population of Cambodia is over 14.8 million with an annual gross domestic product (GDP) of USD 802 (National Institute of Statistics, 2010) per capita. According to the World Bank (2011), Cambodia is one of the poorest nations with $35 \%$ of the population living in poverty. Jin (cited in Rany, Zain \& Jamil, 2012a) reported that low educational quality is one of the key factors leading to unemployment and poverty in Cambodia.

Cambodia is a small war-torn country with a very long history of civil war, political violence and instability. Unlike some countries, during the 1970s Cambodia did not experience an increase in the quality and quantity of higher education but, rather, an unprecedented loss of human resources (Chet, 2006). The consequences of the war during the brutal period of the Democratic Kampuchea (Pol Pot) regime from 1975-1979 on the country's education, health, infrastructure, and judicial systems was considerable and with a lasting legacy. After the war ceased, the Cambodian government, with considerable external assistance, was very busy rebuilding its basic education and until recently it has meant that less focus has gone into higher education. The next step for the country's educational goals is to rebuild a modern higher education system to fulfil the country's internal needs for a skilled and educated citizenry, as well as to respond to external demands and innovation. Reform has recently become the focus of the Cambodian government where the secondary and higher education sectors are now prioritized by the government. Higher education in Cambodia has a central 
role in preparing skilled individuals for the workplace and future leadership roles. However, according to Chet (2006), a lack of human and financial resources has made it difficult to keep parity with other countries in the region in terms of development, despite efforts made by government. In this sense, within this educational context, academic staff are human resources crucial to the development of Cambodian education.

Between 1997 and 2007, the Cambodian higher education sector underwent massive expansion. UNESCO (2006) reported that Cambodia had only one university in 1996, but by the year 2005 it had 51, most of which are private institutions. The number of higher education institutions has been increasing dramatically since then. Presently, according to Rany, Zain \& Jamil (2012b) there are 91 Cambodian higher education institutions, which comprise 34 public and 57 private universities, in 19 out of 24 provinces and in the capital. The numerous higher education institutions are under nine different parent ministries and offer a wide range of courses from associate to doctoral degrees.

Because of the fast explosion of numbers of higher education institutions, Cambodia higher education has been analysed by different educational experts as "a cause for concern," "plagued with difficulty," and "in a ferment of concern." (Rany, Zain \& Jamil, 2012b, p 234). Moreover, the lack of clear structures and policy in the public sector, the boom in private higher education institutions and continued corruption have resulted in both low quality education and research standards in Cambodia's higher education institutions (Innes-Brown, 2006). Rany, Zain \& Jamil (2012b) added that due to insufficient salaries and incentives in public universities, teachers choose to take up part-time teaching at a number of institutions. In addition, without enough income from a normal teaching load, teachers have to spend more time on additional teaching to make a living, rather than engaging in research or professional activities.

\subsection{The research problem}

The strength of an educational system largely depends upon the quality of its teachers. It is a teacher who is instrumental in transforming an individual into a person of imagination, wisdom, care and enlightenment, and the country into a learning society (George \& Sabapathy, 2011). Particularly, it is the teachers who give an educational institution its credibility and determine its character (Stembridge, 1990). Teachers are one of the foundational structures of higher education. Within university institutions, teachers play an 
important role in ensuring high quality education (Rasheed, Aslam, \& Sarwar, 2010). Good teaching is not just a matter of knowing one's subject, being efficient, having the correct competencies, or learning all the right techniques (Hargreaves, 1998). Hargreaves (1998) describes good teachers as enthusiastic, passionate beings who connect with their students and fill their work and their classes with creativity, challenge and enjoyment.

As described above, the quality of higher education is still a debated issue in Cambodia. In 2004, Pit and Ford recommended that in the future, Cambodian higher education would need highly qualified, experienced, strong-willed, and committed human resources in order to support a quality education that would underpin socio-economic development. Rowley (1996) explains that motivation plays a crucial role in the establishment and further development of quality in higher education. He also suggests that academic staff motivation is a strong influence on the offering of a high quality learning experience to students. The performance of academic staff determines the quality of teaching that students experience in higher education, and has a significant impact on student learning and thereby on the contribution that such institutions can make to society. The academic staff of a higher education institution are a key resource. Hence, current Cambodian higher education very badly needs teachers who are not only knowledgeable but also highly motivated and committed to their profession and provide their best efforts to contribute to the development of education. Such attributes require considerable motivation on the part of an individual teacher. In order to maintain strong-willed and committed teachers at tertiary level, motivation is an important factor to be explored and understood.

\subsection{Purpose of the study}

The purpose of the study is to investigate the factors that motivate and de-motivate tertiary educators in their teaching careers. The following are set as the main research questions of the study:

Within the context of a Cambodian public university:

1. Why did current teachers choose tertiary teaching as a profession?

2. How do tertiary teachers perceive motivating factors associated with the quality of their teaching? 
3. How do tertiary teachers perceive de-motivating factors associated with the quality of their teaching?

4. How do tertiary teachers perceive motivation that may lead them to leave or to stay in their profession?

\subsection{Significance of the study}

The motivation of Cambodian university teachers is worthy of exploration for many reasons. Firstly, much research has been done internationally into the motivations of teachers in primary and secondary education and into student motivation. However, teachers' motivations for teaching in higher education are rarely studied (Visser-Wijnveen, Stes, \& Van Petegem, 2012). Hence, this study will contribute to the literature on teachers' motivation in higher education.

Secondly, this research attempts to expand on the limited amount of literature presently available concerning higher education in Cambodia. Cambodia's research, especially in higher education is very limited (Ministry of Education, Youth and Sports, 2009). Specifically, very little is known about Cambodian tertiary teachers' motivations for becoming teachers and remaining in their teaching career, especially in higher education. It is important to understand the motivational factors that are influential for Cambodian university teachers. Understanding motivation can help teachers to improve their performance, and enhance institutional effectiveness which, in turn will lead to improvement in the quality of Cambodian higher education.

Lastly, the results of this study may assist academic leaders in understanding the motivational issues faced by tertiary teachers so that they may improve processes and seek potential solutions for improving working conditions.

\subsection{Researcher background}

I have been teaching for approximately 6 years. Prior to commencing this Masters study, I was a full-time teacher at a university in Cambodia, a position I have held since 2006. While I was working at the university, I had many opportunities to observe in myself and other teachers the motivation surrounding the higher education teaching profession. Through my observations and informal talks with other teachers, I noticed that low salaries and no 
performance rewards were de-motivating; good teachers who prepare well, do research, and provide excellent classes get the same low pay as the those who read the same notes to their students year after year. The problem remains unsolved while the causes are not identified. In order to support our income, as the salary provided by the government is insufficient to support living, some teachers are also seen to be taking up full or part time jobs elsewhere thus robbing ourselves of valuable time that could be spent mentoring and nurturing students (Rany, Zain, \& Jamil, 2012b). To some extent, this demand on their time must influence the productivity and quality of teaching, and therefore the quality of higher education. My belief is that unless the real causes are systematically studied, there will not be any evidenced-based solutions for improvement. Therefore, research is needed to analyze and describe the current motivational issues of Cambodian tertiary teachers. For this reason, I was particularly interested to conduct this study to understand the factors which influence tertiary teachers' motivations in their teaching profession in Cambodia. Moreover, my personal role as a teacher in a university in Cambodia prompted me to conduct this research. I believe that a teacher's motivations for choosing and remaining in their profession have a great influence on their teaching practices.

\subsection{Organisation of the thesis}

This research study is organized into five chapters. Chapter One has presented an introduction dealing with background information of the study, the problem statement, research objectives, research questions, significance of the study. Chapter Two provides a review of theoretical and empirical literature on motivation in different settings around the world. Next, Chapter Three explains the methods used for undertaking the research and analysis of data used in this study. It will describe in detail the participants, methods, instruments, tools, data collection, data analysis, ethical considerations and limitation of the study. Chapter Four presents the results of data analysis based in the research questions. Finally, Chapter 5 discusses the findings of the study with reference to theoretical and empirical literature. This chapter draws conclusions, and indicates some implications for practice and policy. The chapter closes by describing the limitations of the study, and making recommendations for further research in this field. 


\section{CHAPTER 2}

\section{LITERATURE REVIEW}

This chapter provides an account of literature related to the study. This review firstly begins with an examination of the concept of motivation, followed by a review of motivation theories. It concludes with a review of empirical studies examining motivation in teaching. Most of the empirical literature discussed is from other countries as very few studies related to the topic have been conducted in Cambodia.

\subsection{Motivation}

Motivation has probably been one of the most often-researched subjects in the fields of psychology and education (Kiziltepe, 2008). Definitions of motivation vary greatly because of the complexity of its concept, and because many authors tend to define it according to discipline-specific theories (Stembridge, 1990; Naseer ud Din, 2008). The Latin root of the word "motivation" stems from the word "movere", which means to move or to carry (Eccles \&Wigfield, 2002). Eccles and Wigfield suggest that motivation is not only about behaviour, but it is a complex internal state which is generally believed to be deeply rooted in human needs and desires. Moreover, motivation can also be seen as a drive within an individual necessary to direct that person's actions and behaviour toward the achievement of certain goals (Abeysekera, \& Abeysekera, 2012). Most definitions describe three components or three basic elements which constitute motivation (Steers \& Porter, 1991). These are:

a. The energising of human behaviour

b. The canalising or directing (channelling) of behaviour by creating a goal orientation for the individual

c. The maintaining and supporting of behaviour.

To put it more simply, motivation deals with the forces that initiate, direct and sustain behaviour towards the attainment of certain goals (Westerman \& Donoghue, 1989). Although a precise definition of motivation is very difficult due to its complexity, the basic meanings of motivation build on or centre around three fundamental elements: needs, drives and goals (Yu, 1994). Yu summarized the basic process of motivation as needs providing the drives to accomplish goals. In the case of the higher educational setting, tertiary teachers may be better 
motivated if their needs have been identified and satisfied. Therefore the basis for understanding motivation of teachers lies in understanding the needs that motivate their behaviour.

\subsection{De-motivation}

Similar to motivation, a clear definition of de-motivation does not exist (Kupers, 2001). Compared to research on motivation, only a few studies have studied de-motivation (for example, Kiziltepe 2008; Menyhart, 2008; Winter \& Sarros, 2002; Yan 2009). According to Kupers (2001), de-motivation refers to "a reduced force for thinking, feeling, or acting" (p. 3). De-motives are the negative counterpart of motives; motives increase an action tendency while de-motives decrease it (Kiziltepe 2008; Yan 2009). Kiziltepe (2008) refers to demotivation as "no more interested in; having no more motivation, vigour, energy, or commitment for; or not having the determinants of motivation any more"(p. 520). Grubsic and Goic (2003) also state that de-motivation can be a "condition of damaged or destroyed motivation" (p.155). However, Kupers (2001) explains that de-motivation is not just an opposite of motivation that results in non-acting or unmotivated behavior but de-motivation may also result in counter-productive behavior.

\subsection{Intrinsic and extrinsic motivation}

\subsubsection{Intrinsic motivation}

According to Lai (2011) and Ryan \& Deci (2000), intrinsic motivation is defined as motivation that is enlivened by personal enjoyment, interest, pleasure, or satisfactions rather than for some separable consequence, external prods, pressures, or rewards. The idea of intrinsic motivation is centred on the motivators within an individual and does not require external motivators. In regards to work, Herzberg (1968) described senses of accomplishment, self-respect, and personal growth derived from performing one's job as intrinsic factors. Ryan \& Deci (2000) and Eccles \& Wigfield (2002) described that intrinsically motivated individuals engage in an activity because of their interest, fun or challenge. Hence, intrinsic motivation can be satisfied by the work itself. The work itself is the main basis of motivation as it provides stimulation, interests, challenges, and opportunities for personal growth and achievement to the individual (Molander, 1996). 
In addition, Ryan \& Deci (2000) have defined intrinsic motivation in terms of the task being interesting while others have defined it in terms of the satisfactions a person gains from intrinsically motivated task engagement. According to Visser-Wijinveen, Ste, and Van Petegem (2012), intrinsic motivation consists of three types of objectives: an intrinsic motivation to know; an intrinsic motivation to accomplish; or an intrinsic motivation to be stimulated and is associated with improved performance.

Intrinsic motivation in teaching is defined as personal and internal enjoyment in teaching, interacting with students, involvement in interesting subjects and fulfilling career targets (Lortie, 1975; Scott, Cox \& Dinham, 1999). However, another motivating factor- an altruistic factor which is the motive to serve people (Kyriacou \& Coulthard, 2000) - is similar to intrinsic factors. In this study, altruistic motives are described as part of intrinsic motivation. Examples of altruistic factors are when teachers are motivated by a willingness to offer service to society (Kyriacou \& Coulthard, 2000; Lortie, 1975; Poppleton, 1989). In short, Dörnyei (2001) describes intrinsic motivation as "the internal desire to educate people, to impart knowledge and values, and to advance a community or a whole nation" (p. 158), which in itself demonstrates a degree of altruism supporting the inclusion of altruistic motivations as being intrinsic.

According to George and Sabapathy (2011), the intrinsic motivators which are concerned with the quality of working life are likely to have a deep and long-term effect because they are inherent in individuals and not imposed from outside. Moreover, intrinsic rewards are the most prominent and satisfying aspects of teaching (Dörnyei \& Ushioda, 2001). Bess (1977) argues that problems of poor teaching in higher education are related to the lack of recognition of the importance of intrinsic motivation in instructional lecturers. He further explained that if faculty members do not "perceive teaching enterprise as a continuing source of profound satisfactions in life, they will rarely have the sustained role commitment that is necessary for creativity and excellence in performance" (p. 244). Expressed simply, intrinsic motivation refers to an intangible reward (reward that is invisible) which encourages one to do or involve themselves in something through interest. 


\subsubsection{Extrinsic motivation}

In contrast, extrinsic motivation is governed by "reinforcement contingencies" (Lai, 2011, p. 4). It requires external rewards or punishments to persuade an individual to perform an action. In other words, extrinsically motivated individuals carry out activities as a means to something instrumental, receiving a reward, or from a sense of duty- doing their job as a requirement or means to an end (Vallerand \& Bissonnette, 1992; Eccles \& Wigfield, 2002). Examples of extrinsic motivators would be compensation for completing a task, fringe benefits, or the work environment and tangible rewards such as power over the students, job security, convenient working conditions and holidays (Mullins, 1999; Sederberg, Cox \& Clark, 1990). Extrinsic motivators can have an immediate and powerful effect but this will not necessarily last for long (George \& Sabapathy, 2011). George and Sabapathy further explain extrinsic motivation as related to tangible rewards often determined at the organizational level and usually outside the control of the individuals (p. 91).

Extrinsic factors are said to contribute to de-motivation through unsatisfactory salary, poor prospects and working conditions, low status and heavy workload (Spear, Gould, \& Lee, 2000). Moreover, according to Umur (2010), a variety of extrinsic factors have been associated with teacher satisfaction, including salary, goals, perceived support from administrators, school safety, job security, the context they live in, the colleagues around them, and availability of school resources.

The literature summarised above provides useful definitions concerning motivation and insights as to how people are motivated to work and enjoy their work. Empirical studies concerning motivation with regard to teaching are discussed in Section 2.5 and 2.6, after the following section on theories of motivation.

\subsection{Theories of motivation}

No one theory of motivation exists. Rue and Byars (1983) stress that "although the theories may appear to be quite different, most of them are not in conflict with one another but rather look at a different segment of the overall motivational process or look at the same segment from a different perspective" (p. 279). Likewise, Stembridge (1990) argues that there is no one theory that has all the answers for explaining human behaviour. Hence, in this current study, several theories of motivation are incorporated as part of the conceptual framework so 
that the results can be drawn from a wide range of perspectives and lenses. This will allow the findings to be interpreted from a holistic understanding of Cambodian university teachers' motivation. The remainder of this section briefly reviews theories of motivation that relate to an individual's motivation to choose and remain in one's job.

Theories of motivation can be classified broadly into two different perspectives: content and process theories (Stembridge, 1990; Rowley, 1996; Schermerhorn, Hunt \& Osborn, 1997). Stembridge (1990) describes content theories as dealing with "what" motivates people; they attempt to explain why human needs change, but not how they change. Content theories include Maslow's hierarchy of needs; Alderfer's existence, relatedness, and growth theory (ERG); Herzberg's motivation-hygiene theory; and McClelland's theory of needs. On the other hand, process theories are concerned with "how" motivation occurs and emphasize the goals by which people are motivated. Vroom's expectancy theory, Locke's goal setting theory, and Adams's equity theory of motivation are process theories. In this study, five theories of motivation from content and process theories will be reviewed: Maslow's hierarchy of needs, Herzberg's motivation-hygiene theory, Vroom's expectancy theory, Locke's goal setting theory, and Adams' equity theory. Alderfer (as cited in Miskel, 1982) argued that content and process approaches should be viewed as being complementary. These five theories cover a range of perspectives relevant to this study. Choosing from both content and process theories allows analysis of both the "what" and "how" aspects of motivation in this study.

\subsubsection{Content theories}

Content theories of motivation emphasize the reasons that elicit behaviour, that is, what causes it and what its intended purpose is (Schepers et al., 2005). To put it simply, content theories centre on the exploration and determination of the factors that motivate people at work (Yu, 1994). Content theories of motivation focus on the dynamics of individuals' needs (McShane \& Von Glinow, 2003) by attempting to identify what factors within individuals and their environments energise and sustain behaviour (Miskel, 1982; Steyn, 2002). 


\subsubsection{Maslow's hierarchy of needs}

Maslow's hierarchy of needs enjoys wide acceptance. Maslow's hierarchy of needs formulates the basic needs assessment for motivational studies in research related to the study of human psychology. Maslow (1943) deduces five needs required by every person which can be presented in the form of a pyramid ranging from lower order to higher order needs:

1. Physiological needs: The lowest level and basic physiological necessities of human needs such as the need for food, drink, rest, clothing, shelter and other carnal needs. In a work context, these levels can be fulfilled if salary and employment are there.

2. Safety needs: If the needs on the previous level are satisfied, a new needs level automatically come into play representing a higher level in the needs hierarchy. This level represents the need for a secure environment. Within a workplace, the individuals want to be assured that they are provided stability (including financial security) and freedom from physical threats and dangers.

3. Belonging and love needs: This level refers to the needs to have social relationships and the need to belong to others. At this stage, the individual is motivated when feedback from group members is given, so that they have a sense of belonging. The individual secures his or her place in a particular group and develop an emotional relationship with others through giving and receiving love.

4. Esteem needs: There are two types of esteem needs, internal and external esteem needs. Internal esteem needs include self-respect, confidence, competence, achievement and freedom in one's competence in dealing with the world. External esteem needs are met when the internal esteem is being recognised and appreciated by others through recognition, power, status, attention and admiration. The individual needs feelings of being valued and respected by the self and significant others. Within an educational context, teachers can become discouraged if they do not feel that their status and self-esteem needs are met. They want to be recognised for their accomplishments. The need for such recognition is partly met by formal recognition, promotion or other acknowledgement (Steyn, 2002).

5. Self-actualisation needs: This highest level of needs refers to the need to fulfil one's potential and to develop one's capacity in order to achieve one's goals. It includes the need for growth, gaining more knowledge, creativity and self-contentment. 
Maslow grouped the five needs into two categories - Higher-order needs and Lower-order needs. The lower-order needs consist of the physiological and the safety needs. These lowerorder needs are mainly satisfied externally. The higher-order needs include the belonging and love, esteem, and self-actualization and are generally satisfied internally. The principle behind the hierarchy is that needs at each level have to be satisfied to some extent before needs on the next higher level can be satisfied. This means the hierarchy of human needs model suggests that human needs will only be fulfilled one level at a time.

\subsubsection{Herzberg's two-factor theory}

Herzberg's (1968) two-factor theory or the motivation-hygiene theory refers to motivators and hygiene factors that can lead to employees' motivation with regard to job satisfaction or dissatisfaction in their work. According to Herzberg, Mausner and Snyderman (1959), there are some job factors that result in satisfaction while there are other job factors that prevent dissatisfaction. Factors which contribute to better motivation and job satisfaction are called motivators. Motivators are factors that generate a long-term positive influence on an employee's attitude to their work and motivate them to work harder. These are factors involved in performing the job. Employees find these factors intrinsically rewarding. Herzberg et al., (1959) claimed that "motivation is a function of growth from getting intrinsic rewards out of interesting and challenging work" (p. 113) and includes challenging work, a sense of recognition or achievement, and responsibility.

Hygiene factors are factors which prevent job dissatisfaction, but do not cause motivation. To put it simply, hygiene factors are aspects of an employee's work environment that cause employees to become de-motivated with their job if they are not present. Hence, the hygiene factors cannot be regarded as motivators. Hygiene factors refer to the conditions in the workplace and are extrinsic. Some examples of hygiene factors are salary, relationships, physical working conditions, and so on. Table 2.1 summarises motivator and hygiene factors. 


\begin{tabular}{|l|ll|}
\hline Hygiene Factors & Motivator Factors \\
\hline - Salary & - Meaningful work & \\
- Status & - Challenging work & \\
- Job security & - Recognition of accomplishments & \\
- Working conditions & - Feeling of achievement & \\
- Policies and administrative practices & - Increased responsibility & \\
- Interpersonal relationships & - Opportunities for growth and & \\
- Supervision & & \\
\end{tabular}

Table 2.1: Motivator and Hygiene factors (Herzberg et al., 1959)

\subsubsection{Process theories}

A content theory explains behavioural aspects in terms of specific human needs, specific values, or other factors that drive behaviour and act as motives. On the other hand, process theories focus on how the motives create arousal of certain intensity, leading to a particular behaviour, or how a person comes to act in a certain way (Schepers et al., 2005). Process theories are concerned with "how" people are motivated to act in a certain manner, emphasize the goals by which people are motivated, and the amount of effort paid by individuals during the process. Vroom's expectancy theory (Vroom, 1964), Locke's goal setting theory (Locke \& Latham, 1990), and Adams's equity theory of motivation (Adams, 1965) are process theories.

\subsubsection{Goal setting theory}

Locke's goal setting theory explains that goals and intentions are cognitive and wilful (Locke \& Latham, 1990). They serve as mediators of human actions and are mediated by a person's values, which determine what is advantageous to them. This theory states that goal setting is essentially linked to task performance. Motivation and performance will be high if individuals set specific but challenging goals, and where feedback is given on performance (Locke \& Latham, 2006). In other words, goal-setting theory proposes that a clear-cut and challenging goal is effective for motivating people in work settings and recreational 
situations. For example, when a school principal sets a clear-cut goal that was created by all teachers' ideas the plan becomes well-known and has support from teachers. It will motivate teachers to work better because the teachers will feel that parts of the plan belong to them.

Locke and Latham's research found that specific and difficult goals led to better task performance than vague or easy goals. In other words, the harder the goal, the more a person will work to reach it. However, such influences on performance are mediated by two conditions-feedback, and that the person in question accepts the goal (Locke \& Latham, 1990). Locke and Latham explain that constructive and appropriate feedback guides the employees' behaviours and leads to higher performance than absence of feedback. Feedback is a means of gaining reputation, making clarifications and regulating goal difficulties. It helps employees to work with more involvement and leads to greater job satisfaction (Steers and Porter, 1991).

In the educational context, goal-setting theory can contribute to improve high performance and motivation of teachers in many ways (Mclaughlin, 2005). Firstly, goal-setting allows teachers to exercise the intensity and persistence of effort in their work in order to reach the planned goal. Secondly, teachers are likely to have clearer role perceptions so that their effort is channelled towards behaviours to improve work performance.

\subsubsection{Expectancy theories}

Vroom's (1964) expectancy theory of motivation explains why individuals decide to choose one behaviour over another. It also explains how they make decisions to achieve their valued expectation. He introduces three variables - expectancy, instrumentality, and valence-which force an individual to perform a task. Expectancy is the belief that one's effort will result in the attainment of desired performance, while instrumentality is the belief that a person will receive a reward if the performance expectation is met. Vroom explains valence as the value the individual places on the rewards based on their needs, goals, values and sources of motivation. Vroom suggests in his expectancy theory that tangible or instrumental and intangible rewards will have an effect on human behaviour. This means people will demonstrate an increase in motivated behaviour in a work setting if they perceive a positive relationship between good performance and outcomes or rewards. For example, giving a reward to an outstanding teacher every year has a positive effect on teachers' behaviour; teachers may keep working harder in a competitive way in order to get the reward. However, 
it should be considered that if it is to give a positive effect, the reward must be important to the one who chooses to do the work. If the reward has no meaning or does not satisfy them, it will likely have a negative effect on them. As a result they are not motivated to perform well in their work.

\subsubsection{The Equity theory}

Adams' equity theory focuses on the concept of fairness which individuals desire to have equal treatment in their workplace and this desire influences their motivation (Schermerhorn et al., 1997). The higher an individual's perception of fairness, the greater the motivation level and vice versa (Miner, 2005). Hence, the degree of motivation and satisfaction depends on the level of equity/inequity individuals perceive in their working environment.

Adams (1965) states that individuals compare the effort put into their work (input) and the rewards that they obtain in exchange for their effort (output). Equity theory also suggests that individuals compare the balances of their input and output to those of the others in the same working environment. According to Adams, if individuals perceive an imbalance between what they contribute and what they receive, a tension will develop and they will be motivated by the need to reduce or eliminate the tension. Thus, if people believe that they are treated in an inequitable way, they will react differently to a feeling of inequality. Some people reduce effort in a particular piece of work, become recalcitrant or even become disruptive. Other people seek to improve the outputs by making requests or claims for more reward, or seek an alternative job. If they feel that inputs are fairly and sufficiently rewarded by outputs then they tend to be happy with work and motivated to continue investing their effort. People behave in response to the way they are treated within their surrounding environment, and by colleagues, managers, the system and so on. They therefore must be managed and treated in ways that they perceive as equal.

\subsubsection{Applicability of motivation theories to the study}

All the theories described above, provide explanations as to how people can motivated to work and enjoy their work. An understanding of the theoretical constructs in motivation will help to identify the factors that could motivate teachers in this study and the way that factors may work to affect behaviour. 


\subsection{Teacher motivation}

Motivation is believed to be able to influence three aspects of action: 1) choice-why people decide to do what they do), 2) persistence of a person-how long they are willing to sustain the activity, and 3) effort - how hard they are going to pursue it (Steers, Mowday \& Shapiro, 2004; Sharabyan, 2011). Dörnyei and Ushioda (2001) argue that teaching is considered as a type of human behaviour; therefore, general models of motivation must be applicable to describe it. Accordingly, it can be claimed that motivation to teach determines why teachers decide to teach, how persistent they are, and how much effort they put into their teaching career. Moreover, Owens (as cited in Chindanya 2002) sees motivation as dealing with an explanation as to why people do the things they do. This definition can be applied to explain why some teachers come to work on a regular basis and do as little as necessary while others are full of energy and ideas and do their work enthusiastically. In this sense, motivation is seen as dealing with a teacher's attitude towards their teaching career.

Motivated teachers not only feel content with their jobs, but also are empowered to strive for excellence and growth in instructional practice (Oregon School Boards Association, 2009). Motivated teachers have the effects of increasing the efficiency and effectiveness of an institution in its attempt to achieve its objectives and mission (Stembridge, 1990). According to Neves de Jesus and Lens (2005), teacher motivation is important for many reasons. First, it is crucial for the advance and implementation of educational reforms. It is also significant for the satisfaction and fulfilment of teachers themselves. Moreover, Porter and Steers (1973) stated that teachers' job satisfaction and motivation is associated with lower numbers of teachers' absenteeism and turnover. Hence, teacher motivation plays an important role in an institution's success.

\subsection{Teacher motivation in higher education}

Teachers in higher education play an important role in an institution's success and its standing among students and academics (Rasheed, Aslam, Sarwar, 2010). However, there is also a commonly held belief that the majority of faculty in higher education do not reach high levels of quality in their teaching (Bess, 1977). The more motivated a teacher is, the more likely that such a teacher would be more successful in teaching practice as he or she accepts the responsibility that comes with the calling of a committed teacher (Stembridge, 1990). As 
Bess (1977) remarks,"...better teaching will follow from motivated faculty-faculty whose most important needs are being met continually" (p. 256).

Some empirical studies have investigated factors that motivate and de-motivate teachers in higher education. Abdul Cader (2012) studied factors that affect university teachers' motivation in Saudi Arabia. The findings show six important factors that affected teachers' motivation: 1. intrinsic motivation (passion for teaching, a sense of pride in teaching, students' accomplishment); 2. extrinsic motivation (pay increase; programme structurerestrictions placed upon faculty by the management; management support and recognition; and support for professional and personal development); 3. cultural adaptation (culture, language and religious adaptation); 4. management between male versus female supervisors; 5. Nepotism; and 6. modern and new technology.

Morgan (1974) and Stembridge (1990) studied university teacher motivation in the United States. In their studies, achievement and recognition were found as the two most important motivators. Bahrami et al. (2012) studied job motivation factors at an Iranian medical university and found that job security was the most powerful motivator followed by physical work environment, professional development and career advancement. In Argentina, Pinto and Pulido (1997) found that internal rewards along with a feeling of accomplishment, selfachievement and social respect were the most motivating factors, while financial reward was the least motivating. A survey study conducted by $\mathrm{Yu}$ (1994) on Hong Kong Polytechnic teaching staff revealed that teaching staff are motivated both by intrinsic factors derived from teaching, research work and promotion prospects, and by extrinsic factors such as pay and fringe benefits.

Kiziltepe (2008) conducted research about university teachers' motivation and de-motivation factors towards their profession in a public university in Turkey. The findings reveal that student-related factors most commonly affected teachers' motivation. Students' esteem for teachers and students' achievement in their own learning were the most common motivating factors, while poor performance and attitude among students were the most common demotivating factors. Career development, high social status, and ideals about contributing to society were the other motivating factors. Other de-motivating factors also included economic difficulties (that is low salary and accessing funds for professional development), lack of structural and physical characteristics (such as big classes, lack of teaching materials), 
inadequate opportunity and time to do research, and working conditions. Similarly, Winter \& Sarros (2002) found that role clarity, challenging tasks, and supportive leadership are motivating sources for academics in four Australian universities. They also found that role overload, low job feedback, lack of participation in decision making, and administrative tasks were de-motivating academics. In contrast, Menyhart (2008) found that motivating factors were all intrinsic, for example they say teaching is an interesting and valued job which allowed intellectual development of both teachers and students, as well as a sense of importance in being teachers. However, de-motivation was caused by stress and lack of resources and equipment. Menyhart explained sources of stress as low salaries that force teachers to take part-time jobs, job insecurity, lack of autonomy and not enough time to cover all materials in the curricula.

Chindanya (2002) conducted research in South Africa. He found that some factors which enhance motivation are: opportunities for advancement and achievement, recognition, characteristics of the work, opportunities for personal growth and responsibility, and participation in goal formulation and decision-making. While some de-motivating factors are: inequitable distribution of performance related rewards, lack of physical work environment, lack of administrative support, salary, poor and inequitable administration management policy

Resheed, Aslam \& Sarwar (2010) explored motivational issues for teachers in a university in Pakistan. They found that compensation or high salary was the strongest factor that motivated teachers. The authors emphasized that financial constraints are strong concerns for people in developing countries like Pakistan. They also identified other potential factors for motivating teachers such as job design (amount of workload), work environment, career development, recognition and rewards, feedback, training, participation in decision making, and empowerment.

The above discussion concerning empirical studies of factors which influenced university teachers' motivation in different contexts heightens the need to explore Cambodian university teachers' motivation. Which factors influence Cambodian university teachers to choose and remain in their teaching profession? 


\subsection{Teacher motivation in Cambodia}

Research on teacher motivation in Cambodia is scarce and no studies have been located examining tertiary teacher motivation. However, some studies have been done with teachers in basic education from primary to high school education. A review of Cambodian teachers' motivation in basic education is now discussed in order to give a picture of how teachers in Cambodia have experienced motivation. Although basic education is different from tertiary level teaching in Cambodia, they share many similar characteristics as both sectors fall under the jurisdiction of the Ministry of Education, Youth, and Sport.

According to the study of teaching in Cambodia by Benveniste, Marshall and Araujo (2008) concerning entry into the teaching profession, a dedicated group of teachers in Cambodia actively pursued their teaching as a life career. Teaching was the top choice as a profession of the majority of teachers (96 percent) interviewed in the Public Expenditure Tracking Survey (PETS). Fifty-eight percent of the teachers liked teaching as an activity, 21 percent followed their belief on the importance of education, and 13 percent stated that they did not have better professional alternatives. Considering current motivation to remain as teachers, 69 percent of interviewees still preferred the profession and valued its importance; others stressed the socio-economic aspects of this and other professions. Particularly, 18 percent of teachers continued in the profession because they lacked alternative opportunities, while 7 percent of others did it because they thought about job security, and 2 percent stated that teaching provided time to engage in other professional activities.

According to the research on teacher matters in Cambodia done by Nock and Bishop (2008), the most common reasons why teachers chose teaching as a career were a strong interest in the job, a wish to help Cambodia's development by improving education, and enjoyment of communication with children. The proximity of the school to home was an important factor for most teachers, but because of the greater need for teachers in a remote area, some teachers stated that they volunteered to leave their own province to go and teach. Others revealed that their family and older teachers urged them to enter the profession at a time when teachers were badly needed. However, teaching was not the first choice of career for some teachers, and they had little choice because they lacked resources or the ability to study at university to be a medical doctor. In addition, enjoyment of the job was the main motivating factor for many teachers in Cambodia; this was shown in various ways. Because of a feeling of 
responsibility and pride, and desire to be a good role model, some teachers were motivated to take up teaching as their career and the feel also continues to motivate them in their teaching. Besides, while some teachers appreciated the job security that being a teacher offered, some enjoyed the exchange of ideas between colleagues (Nock \& Bishop, 2008). Moreover, some teachers felt "called" to be a teacher, and believed that they were helping to develop education. A very strong motivator for teachers in Cambodia was the desire to help the future of the country and preserve its cultural traditions. As one teacher stated "Children must understand the literature and culture of the nation. "When the literature vanishes, the nation vanishes" (Nock \& Bishop, p. 13). In addition, teachers indicated that they were motivated by the need to develop human resources in Cambodia. Several teachers claimed that they wanted to eliminate illiteracy from the next generation. Another teacher wanted to help Cambodian society "to have good spiritual and moral conduct". Hence, the responsibility towards subsequent generations was seen as a motivation by teachers.

Uy (2012) examined factors causing teachers to choose and remain in their teaching career at one high school. The findings reported that teachers chose teaching as a career because of the influence of a parent or previous teachers, personal self-efficacy, and transferring knowledge to children. The study also found that self-achievement and transferring knowledge were the factors that motivated teachers to remain in teaching.

A study conducted by NGO Education Partnership (2012) on the impact of monetary and non-monetary incentives on primary school teacher motivation found that the most common reasons for entering the profession and being motivated in their teaching are that teachers want to help students have knowledge and a good education, contribute to society and love teaching. On the other hand, the study also reported that de-motivating factors which discourage teachers in performing their professional work are low salary, poor management from supervisor/director, salary delay, and limited professional development. Regarding salary, $87 \%$ of teachers felt that their salary did not reflect the value of their work. As a result of low salary, $67 \%$ of teachers were forced to do a second job in order to secure their income. The study revealed that the engagement with the second job had negative impacts on teaching performance.

These studies show some factors which contribute to primary and secondary teachers taking up the teaching profession and factors which motivate and de-motivate them in their teaching. 
As there is no research about teacher motivation at tertiary level, there is a need to investigate teacher motivation in higher education in Cambodia.

\subsection{Conclusion}

This chapter has presented a review of the theoretical and research literature relevant to the motivation of tertiary teachers. It has highlighted a gap in research literature with respect to Cambodian tertiary teachers. The definition of motivation and teachers' motivation, and theories examined will provide a useful basis that will inform data collection process, analysis of the data and findings of this study. The next chapter presents the methodology used in this study. 


\section{CHAPTER 3}

\section{Methodology}

This chapter describes the methodology used for this study. The following sections include a description of the research paradigm, research design, context of the study, nature and recruitment of the participants, data collection tools, and data analysis. The trustworthiness of the findings, ethical issues raised in the conduct of the research and how they were addressed, and limitations of the study are then discussed. Finally, a summary of the chapter is provided.

\section{$\underline{\text { 3.1 Research paradigm }}$}

According to Cohen, Manion and Morrison (2007) and Davidson and Tolich (2003), the term "paradigm" is used to determine how a researcher pursues the study of a phenomenon in the scientific and social arenas. The two classical research paradigms, normative and interpretive, describe the researcher's ontological, epistemological and methodological premises and are often viewed as opposite and polarized anchors (Cohen et al., 2007; Davidson \& Tolich, 2003). Whereas the normative paradigm stems from the natural sciences with a deductive approach to research where a theory is generated and the research aims to prove or disapprove it, the interpretive paradigm uses an inductive analytical approach on data gathered so that the researcher can grasp the subjective meaning of the social action (Bryman, 2008; Cohen et al., 2007). These paradigms are commonly, but mistakenly, interpreted as being in conflict with one another (quantitative versus qualitative) when this is not really the case at all (Davidson \& Tolich, 2003). Bouma (1998) concludes that "the difference between quantitative and qualitative research is not one of better or worse but rather one of appropriateness to the question asked" (p. 172).

Starting with a clear idea of which paradigm is going to be used is crucial for an educational researcher. As Sekaran and Bougie (2010) state, this step helps researchers to design the research in a specific way so that the requisite data can be gathered and analyzed in order to meet its purpose. In this case, interpretive methodology has been selected as the most appropriate approach for this research study in order to investigate the factors that motivate and de-motivate tertiary educators in their teaching careers. The interpretive paradigm, which has its foundations in anthropology, sociology and psychology is appropriate as it places an 
emphasis on gathering data to interpret and understand social interactions, social meaning and the social context in which people act (Bryman, 2008; Johnson \& Christensen, 2008). In other words, interpretive research methods focus primarily on the kind of evidence that people tell the researcher and what they do, and this enables the researcher to understand the meaning of what is going on (Sekaran \& Bougie, 2010). An interpretive paradigm therefore provides insights on specific problems and provides a deeper understanding of social and environmental phenomena, making it highly suitable for this study which investigates tertiary teachers' motivation for choosing and remaining in their profession.

This study draws on a qualitative methodology within an interpretive paradigm. Qualitative methodology is able to represent experience, views and perspectives of participants in a study (Johnson \& Christensen, 2008; Merriam, 2002; Yin, 2012). Miles and Huberman (1994) emphasize that strengths of qualitative data depend upon their "richness and holism, with strong potential for revealing complexity; such data provide 'thick descriptions' that are vivid, nested in a real context, and have a ring of truth that has strong impact on the reader" (p. 10). Qualitative research allows researchers to gain a rich and complex understanding of a particular phenomenon (Denzin \& Lincoln, 2000). According to Johnson and Christensen (2008), qualitative research is used when little is known about a topic or phenomenon and when one wants to discover or learn more about it. Because research on tertiary teachers in choosing and remaining in their teaching careers has never been studied before in the Cambodian context, it is of use and practical to explore and fully describe details of the nature of experience and perceptions regarding university teachers' motivation. Qualitative methodology therefore fits with the research objective.

\subsection{Research Design}

A case study design has been selected to study the phenomenon of tertiary teachers' motivation. A case study is most appropriate to the research objective because it seeks to provide an in-depth understanding and detailed account and analysis of the case (Creswell, 2007, Johnson \& Christen, 2008). Cohen, Manion \& Morrison (2007) emphasize the advantages of case study:

Case studies are a step to action. They begin in a world of action and contribute to it. Their insights may be directly interpreted and put to use; for staff or individual self- 
development, for within-institutional feedback; for formative evaluation; and in educational policy-making (p. 256).

Moreover, a case study focuses on each case as whole unit as it exists in its real-life context (Johnson \& Christensen, 2008). This is related to the research objective which is to develop a holistic understanding of what motivates tertiary teachers to choose and remain in their teaching career. More specifically, this study will use an exploratory case study for two reasons. Firstly, as little is known about tertiary teacher motivation in Cambodia, an exploratory case study is most useful where there is considerable uncertainty about what the situation is really like (Morra \& Friedlander, 1999). Secondly, this exploratory case study can be used to "develop pertinent hypotheses and propositions for further inquiry" (Yin, 2003, p. 6). This study is a single exploratory case study of a public university in Cambodia.

\section{$\underline{3.3 \text { Context of the study }}$}

This study was conducted in one public university in Cambodia. University $\mathbf{A}$ is used as a pseudonym for the university. University A was chosen for this study because the researcher is a teacher at the university and has networks which facilitated data collection. However, she is not a teacher or connected in any way with the departments selected for this study. University A offers a range of undergraduate and graduate programmes in the fields of Science, Social Science and Humanities, and Foreign Languages which form the three main faculties. Under each faculty, there are several departments. The university has been granted partial autonomy by allowing to establish admission criteria, design academic curricula, and charge tuition fee. The university can also receive funds from other resources and Nongovernment Organisations.

The university has over 450 full-time staff of which approximately $75 \%$ are academic staff members who hold tertiary qualifications, including $5 \% \mathrm{PhDs}$ and the rest with Masters degrees and Bachelor's degrees. Almost all younger staff received their Bachelor's degrees from the university and earned their Masters or PhD abroad. They are supported by over 120 administrative and maintenance staff. University A is a typical of a public university in Cambodia in that it is funded by and under direct supervision of the Ministry of Education, Youth, and Sports. For undergraduate level, the university provides scholarships to high school graduate students through selection processes based on high school grades. In 
addition, the university also recruits private (paying) students. There are no scholarships provided for postgraduate level study.

Tertiary teacher recruitment is done through this Ministry. Once teachers become permanent government teachers, they receive a monthly salary from the Ministry. Teachers within the same university follow the same policy and employment contract. However, in addition to their basic government salary, teachers also receive extra pay for the number of teaching hours they undertake. The amount paid varies across departments.

\subsection{Participants}

The participants of the study were university teachers who were currently teaching at University A that has been selected for this study. The participants were selected from two large departments: Department A and Department B and 38 teachers in total were contacted. Large departments provided a bigger sample to choose from and were more likely to provide enough responses and participants for interview and would better protect participant identities. Two departments in different faculties were selected in order to ensure sufficient depth to the data obtained, and some means of participant validation or triangulation. In this research, two departments were selected from among the three different faculties due to time constraints. The period available for data collection was a university academic vacation for almost three months before the new academic year commenced. During this period teachers rarely came to university if there were no emergency contacts from their departments. In Cambodia, teachers are not required for office hours. In other words, they can come just during their teaching hours. Hence, contacting teachers was challenging. The selection of large departments therefore provided a bigger sample to choose from, and was more likely to provide enough responses and participants for interview, and would better protect participant identities.

Permission for conducting this study was sought from the rector of the university before approaching departments and participants. A letter requesting permission from university (see Appendix A) was given to the rector and permission was granted a few days later. Initially, teacher lists from all departments were obtained from the school administrator. Then two large departments from different faculties were selected. The researcher went to the two selected departments, had meetings with the heads of departments, provided verbal information about the study and a copy of the information sheet (see Appendix D), and 
invited them to participate in the study. The two invited department heads agreed that their departments could participate.

The departments provided the names and contact details of teachers within their departments. In each department, the researcher contacted individual teachers by phone or had face-to-face meetings to provide information about the study and seek their participation. Then, the questionnaire with a separated clip of information sheets and consent form (see Appendices $\mathrm{B}, \mathrm{D}, \& \mathrm{E})$ were handed to all teachers in the two departments. Thirty-six questionnaires were returned. Table 3.1 provides background information of questionnaire participants. In order to protect the participants, completed questionnaires were requested to be put in a post box provided in each department. At the end of the questionnaire, a separated page asked for interview volunteers to complete and return a form giving permission to be contacted for interview, their gender, length of experience, and contact details (see Appendix F).

Table 3.1: 36 Questionnaire participants' background information

\begin{tabular}{|c|c|c|}
\hline Bio-data & $\begin{array}{l}\text { Number of } \\
\text { participants }\end{array}$ & $\begin{array}{l}\text { Percentage of total number } \\
\text { of participants }\end{array}$ \\
\hline \multicolumn{3}{|l|}{ Gender } \\
\hline Male & 24 & $34 \%$ \\
\hline Female & 12 & $67 \%$ \\
\hline \multicolumn{3}{|l|}{ Age } \\
\hline $20-29$ & 7 & $20 \%$ \\
\hline $30-39$ & 17 & $47 \%$ \\
\hline $40-49$ & 8 & $22 \%$ \\
\hline 50 and over & 4 & $11 \%$ \\
\hline \multicolumn{3}{|c|}{ Years of teaching } \\
\hline $0-4$ & 8 & $22 \%$ \\
\hline
\end{tabular}




\begin{tabular}{|l|l|l|}
\hline $5-9$ & 14 & $39 \%$ \\
\hline $10-14$ & 2 & $6 \%$ \\
\hline $15-19$ & 5 & $14 \%$ \\
\hline 20 and Over & 7 & $19 \%$ \\
\hline Academic degree & \multicolumn{2}{|l|}{} \\
\hline Bachelors & 4 & $11 \%$ \\
\hline Masters & 30 & $83 \%$ \\
\hline PhD & 2 & $6 \%$ \\
\hline
\end{tabular}

One male and one female teacher from two different levels of length of work experience (short and long-term) were purposively selected from each department for the interview. From the researcher's local knowledge, in this university, disciplines in which teachers are involved or gender may make a difference to their work experience and therefore motivation. Different departments, gender and work experience were used as criteria to select participants so that data could be drawn from a variety of teachers' perspectives on their motivation. Eight participants were selected for in-depth interviews totally. Table3.2 presents the interview participants' background information. Pseudonyms were used to protect the anonymity and confidentiality of the respondents. 
Table 3.2: Interview participants' background information

\begin{tabular}{|l|l|l|l|l|l|l|l|l|}
\hline Participants & IP1 & IP2 & IP3 & IP4 & IP5 & IP6 & IP7 & IP8 \\
\hline Gender & Female & Female & Male & Male & Female & Female & Male & male \\
\hline Age & 33 & 24 & 38 & 31 & 31 & 28 & 29 & 29 \\
\hline $\begin{array}{l}\text { Degree } \\
\text { experience }\end{array}$ & Master & Master & PhD & Master & Master & Master & Master & Master \\
\hline Department & A & 2 & 12 & 2 & 10 & 2 & 9 & 5 \\
\hline
\end{tabular}

\subsection{Data collection tools}

According to Creswell (2007) in conducting qualitative research, philosophy and the guiding questions are important, but the methods and procedures are important too and cannot be overlooked.

The collection of data was conducted at University A during August and September 2012. Data for the study were collected after receiving university approval. A questionnaire and a semi-structured interviewing approach were used to collect data. The researcher devoted the first three weeks of the data collection period to pilot the questionnaire and interview questions with four teachers who were teaching at the University A and were from a similar sample as the intended participants. The participants in the pilot study were not considered for the actual study. The pilot participants were requested to maintain the confidentiality of the questionnaire and interview questions. Both data collection tools and pilot study were conducted in Khmer. 
Table 3.3: Chronological order of data collection processes

\begin{tabular}{|c|c|}
\hline Dates & Activities \\
\hline Week 1 & $\begin{array}{l}\text { - Seeking university approval } \\
\text { - } \text { Gather teachers' list from school administration } \\
\text { - Select the two large departments } \\
\text { - Approach pilot participants }\end{array}$ \\
\hline Week 2 and 3 & $\begin{array}{l}\text { - Pilot questionnaire and interview questions } \\
\text { - Contact and seek consent from two departments } \\
\text { - Finalize the questionnaire and interview questions } \\
\text { according to feedback of pilot participants }\end{array}$ \\
\hline Week 4 and 5 & $\begin{array}{l}\text { - Distribute the questionnaires } \\
\text { - Collect back the questionnaires }\end{array}$ \\
\hline Week 6 & $\begin{array}{l}\text { - Select interview participants according to gender and } \\
\text { length of teaching experience } \\
\text { - Schedule the interviews }\end{array}$ \\
\hline Week 7 and 8 & $\begin{array}{l}\text { - Conduct the interview } \\
\text { - Transcribe interviews }\end{array}$ \\
\hline Week 9 & $\begin{array}{l}\text { - Peer review/examination (Merriam, 2002, p. 31) by } \\
\text { having a colleague at the university cross-check } \\
\text { transcripts with recording } \\
\text { - Validate the transcripts with the interview participants }\end{array}$ \\
\hline
\end{tabular}

\subsubsection{Questionnaire}

The questionnaire is an important tool for data collection in both qualitative and quantitative studies. The questionnaire has its advantages in terms of less cost, quickness of administering and convenience for respondents. Bryman (2008) noted that "questionnaires are more convenient for respondents because they can complete a questionnaire when they want and the speed that they want to go" (p. 218). Since the participants were university teachers who are extremely busy, and in this case was also on their school vacation, a questionnaire was 
therefore more convenient to administer and would cause less disruption for participants (Bell, 1993; Bryman, 2008).

The questionnaire was developed based on the research objectives and questions. Initially, the questionnaire was divided into four different parts: Part I participant's information, Part II Likert-scale statements, Part III Likert-scale motivation factors, and Part IV Open-ended questions. Likert scale statements and motivation factors were selected from several questionnaires used in the research literature concerning teachers' motivation (Abdul Cader, 2012; Rasheed et al., 2010; Stembridge, 1990; Visser-Wijnveen et al., 2012). The English version of the questionnaire was first piloted in August, 2012, with two teachers who are teaching in other different departments, but in the same university. The objective of the pilot questionnaire was to refine the questions and identify any problems. Pilot participants were given an information sheet (see Appendix F) and consent was gained prior completing in the questionnaire (see Appendix G).

The second draft of the questionnaire was prepared with some changes to the structure and the content based on feedback from the pilot. For example, the order of statements in Part II was rearranged. Two negative statements were changed to positive statements to avoid participants' confusion in the meaning of statements. In Part III, the order of factors was rearranged to put similar concepts together and a brief explanation of factors was added to help participants fully understand the meaning of each factor. Having refined the questionnaire in English it was translated into Khmer by the researcher. To ensure the accuracy of the content, the Khmer version was back translated into English by a professional translator. Checking verification of the original English version and translated Khmer version and the back translated English was done to ensure the content validity of the questionnaire. The English version of the questionnaire can be found in (Appendix B). The Khmer questionnaire version was ready for the second pilot with another two teachers from that university. It took about 20 to 25 minutes for participants to complete the questionnaire, the duration estimated before conducting the pilot.

Based on teachers' feedback on the Khmer version from second pilot, the wordings of some of the questions were modified to make the meaning clearer. A final questionnaire was ready to hand out to all the teachers in the two departments. Completed questionnaires were placed by participants in the post box provided in each department and collected back within two 
weeks. Following the questionnaire administration it was noted that a few questions may have been confusing as they covered two aspects, but the use of interviews allowed opportunities to clarify the situation. This was not raised as a problem in the trials of the questionnaire.

\section{$\underline{\text { 3.5.2 Semi-structured interviews }}$}

The first phase of the data collection was the questionnaire which has been fully described in the section above. For the second phase of data collection, a semi-structured interview was used. In qualitative research, interviewing is the most popular form of data collection (Jonhson \& Christen, 2008; Lichtman, 2010). According to Johnson \& Christensen (2008), qualitative interviews can allow the researcher to obtain "in-depth information about a participant's thoughts, beliefs, knowledge, reasoning, motivations, and feelings about a topic" (p. 207). Semi-structured interviewing was employed in this study because the researcher can vary the questions as the situation demands which enables more flexibility (Lichtman, 2010; Denscombe, 1998) and obtain a greater depth of insight through probing (Miles \& Huberman, 1994). In this study, semi-structured interviews allowed the researcher to gain deeper understanding of the participants' point of view, elaborate on trends identified from questionnaire analysis data, and to seek more details that emerged from the questionnaire responses (Gay, Mills, \& Airasian, 2009).

As for the questionnaire, the interview questions were translated into Khmer then back translated into English.. The pilot and actual interviews were conducted in Khmer as several participants could hardly speak English. The use of Khmer avoided misunderstandings and allowed participants to fully and clearly express their ideas.

The researcher piloted the interview with two teachers to improve questions, test timing and to get practice in interviewing. Both pilot participants recommended giving the interview questions to participants prior to the interview because they found some questions hard to provide answers to immediately.

The teachers were invited to participate in the interview firstly through an invitation letter attached to the end of questionnaire with a separate page for volunteers to complete and return giving permission to be contacted, along with information about their gender, length of experience, and contact details (see Section 3.4). Selected participants were interviewed face- 
to-face in a private office setting of their choice at their respective places of work. The interviews were audio-recorded. The participants were given the interview questions (see Appendix C) at least three days in advance. Prior to the interview, the participants were briefed in Khmer on the purpose of the study and the role of the researcher in the entire process. The participants were also allowed to ask any questions before the recording commenced, and reminded that they could ask for the recorder to be turned off at any time.

\subsection{Data analysis}

\subsubsection{Analysis of interview data and open-ended questionnaire data}

No absolute formula, but only guidance, exists for data analysis of qualitative research (Patton, 2002). Lofland, Snow, Anderson, and Lofland (2006) suggested that several ways can be used to approach data analysis, but the researcher is the vital agent who needs to carry out the analysis process persistently and methodically. According to Neuman (2000) the task of the qualitative researcher is to 'form new concepts or refine concepts that are grounded in the data' (p. 420). Neuman also suggested that the qualitative researchers 'develop new concepts, formulates conceptual definitions, and examines the relationship among concepts' (p.420). Patton (2002) suggested that data analysis is guided by the purpose of the study. Investigating the factors that motivate and de-motivate tertiary teachers in their teaching careers is the main purpose of analysis in this study.

In this study, "thematic analysis" was used as the process of the data analysis as identified by Braun and Clarke (2006). Thematic analysis is a method for identifying, analysing, and reporting themes within data (Braun and Clarke, 2006). Braun and Clarke present six phases of analysis.

1. Familiarisation with the data

2. Generating initial codes

3. Searching for themes

4. Reviewing themes

5. Defining and naming themes

6. Producing the report 
Firstly, each transcription was completed soon after the conduct of each interview. Once the information was fully transcribed into each text file, each transcription was visually checked against the audiotape and some minor inaccuracies were corrected. This transcription process and check allowed me as the researcher to become familiar with the data. I read through all the entire transcripts to get general ideas. I then read and re-read in an active way by searching for meanings, making notes at the margin, and using different colours to highlight ideas for initial coding. Once I had familiarised myself with the data, I made an initial list of ideas, and noted what was in the data and what was interesting about them.

The next phase involved the production of initial systematic codes across the entire data set and the collection of data relevant to each code. The coding process was begun. I divided and gave codes to meaningful segments of the data. At end of this phase, I had a long list of the different codes.

Phase three involved sorting the different codes into potential themes and grouping all the relevant data extracts within identified themes. In this process, I created summary tables listing codes, participants and extracts. I examined the relationship among codes and played around in order to organise into themes under headings created from the four research questions.

The fourth phase was reviewing and refining themes. This phase was done in two levels. Level one was to examine coherent patterns between themes and their collated extracts. If themes did not fit, I reworked the themes by creating a new theme or discarding them. Level two involved developing a holistic coherent pattern of each theme with the entire data. In other words, each theme was reviewed in relation to all the data so that additional data within themes could have been added in case there were any missing data in the earlier coding process. This process was repeated until the "thematic map" fitted with the data set.

Phase five was to define and name the themes. This stage involved "identifying the essence of what each theme is about (as well as the themes overall) and determining what aspect of the data each theme captures" (Braun \& Clarke, 2006, p.92). In addition to providing definition and detail of each individual theme, I also considered how all the themes fitted in broader overall descriptions to the four research questions and how the themes related across all the four questions. 
The final phase was to write the report after final themes have been reviewed. In this phase, it was important that analysis of data was well reported within and across themes by providing typical extracts and evidence from the data.

\subsubsection{Likert scale questionnaire data}

A programme called Statistical Package for Social Science (SPSS) was used to analyze Likert scale questionnaire data in order to present basic descriptive data. The numbers of participants for each response were counted. As respondents were required to indicate either a positive or negative position, results for strongly disagree and disagree were aggregated as were those for agree and strongly agree. It is important to note that data was used qualitatively to give perspectives on participants' responses. It is not appropriate to use any further analytical quantitative analysis other than to look at the distribution of responses.

\subsection{Trustworthiness of the findings}

Ensuring and producing valid and reliable findings are important considerations in qualitative research (Patton, 2002; Merriam, 2002). When qualitative researchers speak of research trustworthiness, they are usually referring to qualitative research that is plausible, credible, trustworthy, and therefore defensible (Johnson \& Christensen, 2008). Johnson and Christensen believe it is important to think about the issue of validity and reliability in qualitative research and to examine some strategies that have been developed to maximise them. The subsequent sections discuss in detail issues of validity, reliability and triangulation and how they were addressed in this study. 


\subsubsection{Validity}

Validity is an essential key to effective research (Cohen et al., 2007). According to Merriam (2002), validity includes internal validity and external validity. Internal validity asks the question, "How congruent are one's findings with reality?" (Merriam, 2002, p. 25). This study employed some strategies to ensure internal validity. Firstly, Yin (2003) recommends a pilot test to refine data collection plans and develop relevant lines of questions. Hence, the researcher maintained validity by conducting a pilot study. Prior to fieldwork of this study, pilot interviews and questionnaires were carried out with four Cambodian university teachers who were currently teaching at the university selected for this study. Secondly, the participants were given the opportunity to validate the transcripts and make their opinions clear before the data was analysed. Moreover, to strengthen validity for this study, particularly internal validity, "peer review/examination” (Merriam, 2002, p. 31) was used by having a colleague at the university cross-check transcripts with the recording as well as the English translation. Finally, researcher bias is one potential threat that researchers must watch out for (Johnson \& Christensen, 2008). To reduce the effect of bias in this study, I employed a strategy suggested by Johnson \& Christensen: reflexivity. Reflexivity requires me to actively engage in critical self-reflection about my potential bias. Hence, in Chapter one, I reported my personal and professional information and reflection as a researcher.

External validity refers to the degree which the study is generalisable to other settings (Merriam, 1998). Merriam (2002) suggests that providing rich, thick description in qualitative research is a main strategy to ensure external validity. While this case is not able to be generalised, the research context, procedures, and analysis have been described in detail so that there is enough information provided to readers who may be interested in applying this study's findings to their own situation.

\subsubsection{Reliability}

Bell (1993) states that "reliability is the extent to which a test or procedure produces similar results under constant conditions on all occasions" (p. 64). Reliability is not only about the consistency of the measure of a concept (Bryman, 2008; Cohen et al., 2007; Davidson \& Tolich, 2003) but also the extent of dependability of the research's findings (Merriam, 2002). Denscombe (2010) suggests that reliability is maintained by providing a clear explanation of 
research procedures. In addition, according to Creswell \& Miller (2000), reliability has been assured by providing a clear audit trail and stating the researcher's position. In this study, the research procedures and activities as well as the researcher's position have been clearly reported. Cohen et al. (2007) point out that reliability in qualitative research is concerned with the consistency of what the researcher records as data and what really occurs in the natural setting of the research so that the coding and intentions of participants are constantly checked to maintain the degree of reliability. For this study, the interviews were audiorecorded and transcribed so that the participants were given the opportunity to check for accuracy.

\subsubsection{Triangulation}

Triangulation is an important technique of ensuring and strengthening validity in qualitative research (Bryman, 2008; Yin, 1994). According to Bryman (2008), and Cohen et al. (2007), triangulation could be done by the use of multiple methods or multiple sources of information to generate data as a validation procedure in order to strengthen the credibility of a study. This research was triangulated by the use of semi-structured interviews and questionnaire as data collection tools. Furthermore, the study was strengthened by using multiple participants across two different departments; hence, the results were drawn from a wide range of perspectives of various participants.

\subsection{Ethical consideration}

Ethical issues related to data collection and reporting were taken into consideration by the researcher. Davidson and Tolich (1999) suggest five key principles for ethical considerations: do no harm, voluntary participation, informed consent, avoid deceit, and ensure confidentiality and anonymity. This study was approved by the Victoria University of Wellington Human Research Ethics Committee and it conformed to New Zealand Association for Research in Education ethical guidelines (NZARE, 2010). I had a professional obligation to protect the identities and interests of the research participants at all times and to ensure that they were not harmed by my research. The participants are in employment in a hierarchical situation where information about their motivation may damage their careers if they were able to be identified. They may lose their job or their relationship with management may be damaged if they were to criticize it. I protected my participants' rights to privacy through the provision of confidentiality. In this research, all participants 
were voluntary and they could withdraw at any time, they were guaranteed that the data and the identity of their university and faculties would be kept confidential. Hence, the names of the university, the participants and the departments were kept confidential and pseudonyms used to assure that their professional integrity was not compromised by anything they contributed to the study.

Cohen, Manion and Marrison (2007) identify that the fundamental principle of ethical inquiry is that of informed consent. A formal written request with information forms was made by letter to rectors and both faculties in order to gain permission and access. Participants were briefed on the ethical considerations of the study in order to increase the level of trust between the researcher and the participant. Participants were fully informed about research purpose and procedures, and consents were obtained before data collection took place.

Besides the researcher and supervisor, interview data was seen by a transcriber. To protect participants' confidentiality, recordings and transcripts were labelled using pseudonyms. The transcriber signed a confidentiality agreement (Appendix I). All the data obtained from participants was securely kept in a locked file and access was restricted to the researcher (Bouma, 1998; Cohen et al., 2007). The audio recordings were kept in a password protected external hard-drive and will be destroyed at the conclusion of the research. Overall, the research design was such that it minimised harm to participants while still achieving the research aims.

\subsection{Limitations}

The limitations of the study are now discussed. Firstly, this study only engaged two departments in a public university. This is a very small sample compared with the number of departments within the university. As Cohen et al. (2007, p. 102) stated, "sample size can be constrained by cost - in terms of time, money, stress, administration support, the number of researchers, and resources". This research sample size was considered carefully in the sense that data collection was manageable. It is also important to note that this study was not aimed to make any generalizations to other different contexts. However, a larger sample may provide richer and more insightful data.

Secondly, the teachers who participated in this study were those who are currently teaching. The responses of those who have left may be different. The findings might have been 
different if teachers who had already left the profession had participated in the study. Time and the size constraints of a Masters study did not allow for the inclusion of such participants.

\subsection{Conclusion}

This chapter has outlined and justified the research design, the selection of participants, the data collection methods, and procedures involved in analysis of the data. Issues related to trustworthiness and ethical considerations were also discussed in detail in this chapter. The next chapter presents a description of the findings. 


\section{CHAPTER 4}

\section{FINDINGS}

This chapter reports on the data collected in the conduct of the research from a public university in Cambodia. Analysis of data from both interviews and questionnaires has identified and contributed to understanding factors that motivate and de-motivate tertiary educators in their teaching careers in this context. It is noted that the findings revealed no obvious difference between responses of participants of different genders and length of experience; responses of all participants contributed to the findings presented here. The data is described in themes that emerged in the process of the data analysis to address four research questions within the context of a Cambodian public university:

1. Why did current teachers choose tertiary teaching as a profession?

2. How do tertiary teachers perceive motivating factors associated with the quality of their teaching?

3. How do tertiary teachers perceive de-motivating factors associated with the quality of their teaching?

4. How do tertiary teachers perceive motivation that may lead them to leave or to stay in their profession?

\subsection{Research Question 1}

Research Question One asked why current teachers chose tertiary teaching as a profession. Analysis of data from the open-ended section of the questionnaire, supported by data from interviews revealed the themes described in the following sections.

\subsubsection{Helping younger generations and contributing to society}

A common motivating factor for choosing tertiary teaching was helping the younger generation and contributing to society. Analysis of the questionnaire data concerning teachers' reasons for choosing tertiary teaching as a profession showed that teachers were keen to share their knowledge to build a more confident generation who will contribute to 
their country's development. Helping the younger generation was the most common response to the open-ended question section of the questionnaire: "What factors influenced you the most in deciding to become a tertiary teacher?", being mentioned by 18 of the 36 respondents. Eleven participants provided the reason of contributing to society. These findings show that helping students learn and imparting knowledge are the most common reasons that the participants decided to take up teaching. They see themselves as important agents in society's development.

This finding is supported by interview data. Helping the younger generation was the second most common reason stated by the interview participants. Having the opportunity to transfer what they know to their students made them enthusiastic for their profession. IP3 felt he could directly contribute to society through his teaching and education.

One participant excitedly stated:

Another important factor in becoming a teacher is that I can transfer my knowledge to other people. If I worked somewhere else, I could show my ability but not transfer knowledge. Transferring knowledge is what I am really keen about (IP8).

Another participant considered tertiary teaching a role where he is able to help students and contribute to education at improvement. He stressed:

I think that by becoming a tertiary teacher I have the opportunity to meet and transfer knowledge to students ... also help the society. I feel that social development is mainly through education. If the education is poor, social development would not exist (IP4).

\subsubsection{High social status}

The high social status of the teaching profession was the most common response concerning the motivation to join the profession in the open-ended section of the questionnaire. Eighteen out of 36 participants provided this reason. Moreover, in response to the statement "The teaching profession has a high social value", the majority of participants agreed while only four disagreed, showing that the status of the profession was important to the participants. These teachers perceived that the teaching profession is highly valued by society.

Three of the interview participants also said that they wanted to be a teacher because of the high social status of the teaching profession. For instance, IP2 and IP3 commented that the 
teaching profession is valued by society and that many people admire and respect this profession.

\subsubsection{Personal interest in teaching}

Questionnaire data showed that personal interest was one of the most commonly mentioned motivating factors for becoming a tertiary teacher. The participants had an interest in teaching and wanted to teach as a career choice. In the open-ended question asking what factors influenced the participants the most in deciding to become a tertiary teacher, 11 participants referred to personal interest as one of the factors. In addition, in response to the Likert scale statement, "Teaching was always what I wanted to do", 29 participants agreed while 5 disagreed and 2 strongly disagreed. Thus, the majority of the 36 participants had teaching as their goal. What is more, the majority showed enjoyment of teaching: Thirty-three participants agreed or strongly agreed in response to the statement in part II of the questionnaire "I enjoy teaching".

Interview data also showed that personal interest was a primary reason for the participants choosing teaching as a profession. Six interviewed participants mentioned that they had an interest in teaching which influenced them to take up teaching profession. IP5 responded, "Actually, it was my natural interest. I always liked teaching." Notably, although one of the 6 teachers, IP8, seemed to have hesitation before he really decided to become a teacher, he still chose teaching as his career. He described that he had teaching as his goal when he was young but he wavered when he was studying at university. At the end, he still chose teaching as his career because of his initial interest and also a slight influence of his parents' advice. The underlying question is what creates this personal desire to teach? It may be linked to personal satisfaction. The participants were enthusiastic about teaching: "Teaching is my personal interest because when I teach someone and they learn, I am happy. When I explain something and they understand, I am extremely glad" (IP3).

\subsubsection{Upgrading knowledge and skills}

In response to the questionnaire, 10 participants identified upgrading their knowledge and skills as their reason for becoming teachers. They defined tertiary teaching as the level at which they are able to seek more extensive and profound knowledge. For example, three 
participants said that they wished to develop further knowledge and understanding through further study or a scholarship abroad.

Three interview participants also cited upgrading knowledge and skills as the reason that influenced them to choose teaching as profession. They said that being a teacher was not all about teaching; it allowed them to learn at the same time. For instance, IP4 claimed that she enjoys upgrading her knowledge. When she teaches, she researches her teaching subject. Hence, she can develop up-to-date knowledge. Another participant explained:

I understand that being a tertiary teacher, I have many more opportunities to involve myself in research. Therefore, I can also develop myself. If teaching at high school, I mainly could directly apply rudimentary knowledge. I could not expand. This is why I decided to become a tertiary teacher (IP5).

IP6 similarly described that teaching at tertiary level allowed her to enhance her knowledge more than at high school level. If at high school she could not develop, she could only know what she had already learned. Teaching at tertiary level, she receives far more opportunities for further study and study abroad than if she were teaching at a provincial high school.

\subsubsection{Circumstance}

In addition to the factors discussed above, questionnaire findings demonstrated that circumstance was also a factor in nine participants becoming teachers. Circumstance described situations such as participants going into teaching because of their particular educational background, while for others it was not their first choice of career, or the coincidence of teacher recruitment with the time they were looking for jobs.

Circumstance was also one of the factors indicated in the interview findings. For example, IP1 described that soon after she finished her masters degree, there was an announcement about teacher recruitment, specifically of female teachers. She asked herself why she would not take up this opportunity. She decided to apply and was accepted. IP7 reported that teaching was not what he intended to do. He had aimed to be a doctor, but owing to financial constraints he was not able to study at a university of medicine. His bachelor degree enabled him to apply for a teaching position which was announced just as he completed his degree. He then applied and was accepted. He also did not expect to teach at tertiary level, but he was selected for university teaching because of his good grades. 


\subsubsection{Salary and living standards of teachers}

Among open ended questionnaire responses, salary was a factor identified by several participants as a reason for taking up tertiary teaching. Eight participants stated salary as a reason for becoming a tertiary teacher. Tertiary teachers are paid reasonably high salaries in comparison with other teachers. Also, besides receiving their government salary, they have opportunities to teach additional classes, for which they are paid at an hourly rate.

Interview data also demonstrated that the living standard of teachers was an influence on career choice. Living standards relate to salary but also include other factors. Three interview participants reported that the living standard of teachers was their reason for choosing tertiary teaching. IP3 said, "A teacher has a simple life with decent living which is not too rich or too poor. This is what I want." Similarly, IP8 explained that to him, the living standard of teachers was not so bad. It was simple and average. IP6 considered that teaching at tertiary level would provide her a higher salary than if she taught at high school.

\subsubsection{Characteristics of the profession}

Another theme which emerged from the questionnaire findings was that the characteristics of the profession were attractive. Five participants reported that the characteristics of the teaching profession influenced their choice. They explained that they saw teaching as a job which was unpressured and independent. It allowed some time to relax. One participant also mentioned that he thought he would have some spare time to work outside the university. As this study focuses on a university that is government-owned, three participants also revealed that they decided to choose teaching because they would be government staff. Becoming a government teacher was seen as a stable job, allowing them to work until they retire.

Some interviewed participants also considered becoming a teacher because of the characteristics of the profession. IP4 explained that teaching was a flexible job. He could manage his time. It was not a job that required working 8 hours a day full-time. Outside of teaching hours, he could do other things. IP8 stated, "I have some time to relax, take a vacation. It is good. If I worked in a company, I would not have time to relax. It is a great point of the teaching profession." IP1, who did not initially like teaching, started to enjoy her profession because she found that teaching was a job that gave her independence. 


\subsubsection{People influence}

Findings of the open-ended section in the questionnaire showed that eight participants were influenced by their parents, former teachers, and classmates in their decision to become a teacher. Also, in response to a statement "My choice for becoming a teacher was influenced by my parents or my previous teachers", 18 participants agreed which is 50 percent of the questionnaire participants. This finding shows that the "people" factor has a moderate influence on participants' choice of teaching as a career. This finding may be able to be explained from cultural perspective that Cambodian parents often have influential authority on their children's career choice.

People who influenced interviewed participants were parents, family, and former teachers. Two participants mentioned their parents as influences in their becoming a teacher. IP2 said:

My family, especially my parents, strongly encouraged me to become a government employee. Soon after I finished my masters, I planned to open a business company. When my sister saw an announcement on teacher recruitment, she insisted I apply. Then I applied and was accepted. My parents also pushed me to take the job.

Another participant also explained:

When I was young living in my village, I thought being a teacher has a decent living. I wanted to become a teacher. However, while I was studying at university, I changed my mind. I didn't want to become a teacher... Later I decided to become a teacher because of my parents. They wanted me to be a government employee or a government teacher. Hence, I finally decided to become a teacher (IP8).

IP8 also said that because of assistance from his former teacher who was at that time the head of department, he was able to teach at tertiary level.

I was actually assigned to teach at a high school, but the former head of this department liked me and thought I would be better teaching at tertiary level. He therefore requested me from the Ministry. This is how I became a teacher here (IP8). 


\subsubsection{Undertaking research}

The final factor identified as influential in participants choosing tertiary teaching as their profession is the capacity for research. While no participants mentioned research as the factor in the questionnaire responses, research is an influential factor emerging from interview findings. Most participants did not initially aim for tertiary teaching. They were simply interested in teaching and they did not specifically refer to the tertiary level. However, two participants referred to research as their reason for becoming teachers, particularly tertiary teachers. IP4 stated, "I think tertiary teachers do not solely teach, but what is more important is research, which is my main interest. I like research.” Another participant explained:

Actually, it was my natural interest. I always liked teaching. At first, I did not think about teaching at tertiary level. I just desired to become a teacher. But when I studied at university, I had the opportunity to do research. The first research was my thesis to complete my bachelor study. After that I considered teaching at tertiary level would have lots of opportunities to research. This drove me to become a tertiary teacher (IP5).

Overall, the findings from the interviews and the questionnaire addressing Research Question One regarding which factors influenced the participants to become tertiary teachers, revealed that participants were influenced to choose teaching as a profession so they could help the younger generation and contribute to society. Teachers were motivated to teach because of its high social status, a personal interest in teaching, a wish to upgrade knowledge and skills, circumstance, salary and living standards of teachers, characteristics of the profession, influence by people, and opportunities for undertaking research. It was found that intrinsic and altruistic factors were generally rated as more important than extrinsic factors, although both intrinsic and extrinsic factors contributed to participants choosing tertiary teaching as a profession.

In considering these findings, it should be remembered that this research question required the participants to look back at their motivations prior to starting teaching. The participants may have used hindsight while responding to these research questions. Their perspectives are retrospective in nature and may reflect current motivations. Motivations associated with teaching are discussed next. 


\subsection{Research Question 2}

This section reports on findings to Research Question 2, on how tertiary teachers perceive motivating factors associated with their tertiary teaching profession i.e. the factors that they perceive motivate them to teach well. Data from Part II and III in the questionnaire and from interviews addressed this question. After analysing the interview data, it was found that the participants' responses concerning motivating factors in their teaching profession can be classified into two different types: current motivating factors and potential motivating factors. Current motivating factors refer to factors that the participants are currently experiencing that support them to want to teach well. On the other hand, potential motivating factors are factors that were desired and suggested from interview participants that they felt would support them to teach better, but were not currently experienced in their job. Potential motivating factors refer to opportunities that would motivate the participants to deliver their most effective level of performance in their teaching profession.

\subsubsection{Current motivating factors}

\subsubsection{Helping younger generations and contributing to society}

As in section 4.1, questionnaire data revealed that helping the younger generation and contributing to society were the most common motivating factors for teachers currently in their teaching profession. In response to a statement in part II of the questionnaire, all 36 participants agreed to the statement "I enjoy working with students" with 22 participants strongly agreeing. Only one of 36 participants disagreed with the statement "I will be able to help younger people and bring about change to education", while the others all agreed, 23 participants strongly agreeing. Part III of the questionnaire required participants to rate the level of importance of a variety of factors. Data from this showed that helping the younger generation and contributing to society were highly motivating factors to participants. Thirtyfour participants rated helping younger generations as important or highly important, while 35 participants marked contributing to society as important or highly important.

This finding was supported by interview data which showed that helping the younger generation was the most common motivating factor among interviewed participants, both for remaining in the teaching profession, as well as for encouraging the teachers to take up teaching, as described in the previous section. Six participants stressed that they were 
delighted to see their students' achievements after their teaching. IP2, IP3 and IP6 explained that the major motivating factor was students. They were very content when they received respect from their students. They enjoyed teaching the students. When they gave the students assignments, the students enjoyed and worked hard on those assignments. The students received good grades. The participants felt motivated and capable. They were delighted to see the students get good jobs and achieve good positions. The participants were keen to transfer their knowledge to the younger generation. IP7 said, "I have learned from my teaching and I want to transfer what I know to my students so that they can further develop themselves".

For IP5, helping the younger generation not only motivated her to remain in the profession but drove her to love teaching even more, because helping the younger generation also reflects her contribution to society. She said:

Every year I am really contented to see my students' outputs. From my teaching, the students learn, graduate, and get good jobs. Some outstanding students get scholarships abroad. I consider that I have created human resources for society from my teaching. This is what really inspires me to love and put more effort to my teaching. So, I feel that my teaching produces successful outcomes.

Likewise, IP8 explained how his teaching contributed to future social development. He described that Cambodia was stabilising as a nation, which provided an excellent opportunity for him to push his students to study hard. If those students studied very hard, he predicted that in the next 20 years or so, the country would be as developed as neighbouring countries. He saw his university as a great place because he was able to push the students to work hard. He felt that he made a huge contribution to improving education.

Another participant gave an example of how his teaching contributed to society. He told how many students he taught in just one classroom. Those students may educate other people or work somewhere. If he teaches more classes, his contribution is bigger. He believed that social development occurred through education. If education is poor, future social development is also limited.

\subsubsection{Upgrading knowledge and skills}

Upgrading knowledge and skills was the second most common current motivating factor mentioned by the questionnaire and interview participants. According questionnaire data, 
"upgrading knowledge and skills" factor was rated as important and highly important by 33 participants.

Similarly, three interviewed participants indicated that teaching was not only about transferring their knowledge, but also provided teachers with the chance to continually improve themselves. For instance, IP1 reported that she learned a lot from teaching. She had acquired extensive knowledge that she had never expected to acquire. Being in the teaching profession pushed her to grow and master new knowledge.

IP7 described his experience:

I have learned a lot since I started teaching at this university, including foreign languages. I have improved significantly as I got a scholarship to study in New Zealand... In my opinion, being a teacher, we learn almost every day. Even if we do not have class tonight, we still need to think of what we are going to teach next time.

IP2 emphasised the ongoing contribution of her teaching. Her profession motivated her to enhance her knowledge and skills. Once she has developed her own knowledge, her students also benefited because she was able to transfer her upgraded knowledge to the students.

\subsubsection{Devotion to teaching}

Devotion to teaching was another motivating factor associated with participants' teaching profession. All the participants agreed to the statement "I try my best in my teaching duties and being a good teacher". This showed that the participants had the willingness and commitment to their teaching.

Three interview participants also remarked on their devotion to teaching as a motivating factor. They said that besides some external motivation, their internal motivation was vital in keeping them in the profession. IP7 explained, "Teaching is from my willingness, my devotion. Internally, it is really important that I have commitment to what I need to do and what I am going to do."

IP4 stated:

Currently, what motivates me the most is my internal rather than external (motivation). My internal motivation is related to my desire to be a teacher. I do not like to work in a 
fixed place or office. I like to communicate, and teaching allows me to communicate with students. This enjoyment motivates me.

\subsubsection{High social status}

As in section 4.1, an influential motivating factor is that the teaching profession is highly valued in Cambodian society. From questionnaire data, 32 of 36 questionnaire participants agreed that the teaching profession has a high social value. 33 participants circled high social status of teaching as an important factor influencing their motivation.

Moreover, two interview participants described how they felt proud thinking of themselves as being tertiary teachers. IP2 stated, "Many people give high value to the teaching profession especially at tertiary level. People sometimes suggested that teachers are considered to be second parents." IP4 commented, "I am proud when I meet students somewhere and they respect me. Sometimes, they ask for advice. It means as a lot to me. That motivates me." This means that being given high value to their teaching career was important to the participants' motivation.

\subsubsection{Opportunities for further study}

In the questionnaire, 27 participants described opportunities for further studies as important to their motivation. Interview data provided some further insights. Three participants said that opportunity for further study was a current motivation for their teaching. IP4, IP5 and IP6 stated that what keeps them motivated is their aim to study further abroad. IP5 explained, "Although I need to use my own capacity to receive a scholarship for further study, being a tertiary teacher provides me with high potential candidacy. This also motivates me in my teaching." Meanwhile, IP6, who has received her masters degree locally, has set a goal for another masters degree abroad.

IP4 said that being a teacher at tertiary level gave him a stronger chance of studying abroad. He explained, "I think, in the future, our education system will need to be strong as part of Southeast Asian integration. In order to have a strong education system, tertiary teachers will be required to have high qualifications." 


\subsubsection{Characteristics of the profession}

The characteristics of the profession is another important factor in keeping the participants motivated. The teaching profession is an independent profession which allows teachers to have ability to control their own teaching. In this sense, the majority of the questionnaire participants agreed that at university they are empowered to choose and implement their own teaching practices. This means that they have autonomy in their teaching. 34 participants marked autonomy to teaching as an important factor influencing their motivation. Having the ability to control their own teaching motivates tertiary teachers in their teaching profession.

In addition, two interview participants described the characteristics of teaching as a profession kept them motivated. IP4 saw the teaching profession as flexible. He explained:

Teachers do not have to work at (a) fixed time or strictly be in one place like working in a company. Unlike working eight hours a day, five days a week in a company, I am able to do other things after my teaching hour(s).

IP8 also reported that he was happy with this profession because it was an independent profession. He was responsible for decisions about managing his teaching classrooms and he was able to manage his time accordingly. He also liked being able to take a vacation following a period of teaching.

\subsubsection{Undertaking research}

As in section 4.1, research was a motivating factor which 27 questionnaire participants marked as important to becoming teachers. Additionally, research was mentioned by an interview participant. This participant wanted to become a tertiary teacher because of the capacity it gave for research. She also said that research was an ongoing motivating factor along with helping the younger generation. She explained that teaching at university offered her lots of opportunities to involve herself in research. By doing research, she could also improve herself. She ended her explanation by restating that research was what she liked most and that it was a very influential factor for her in remaining in the profession. 


\subsubsection{Potential motivating factors}

Potential motivating factors are abstract because they are suggested by the interview participants as ways of increase the level of teachers' motivation to deliver their most effective level of performance. Potential motivating factors will be reported mainly from data of the interviews.

\subsubsection{Physical working environment}

Analysis of interview findings indicated that a positive physical working environment was one of most commonly desired factors. Six participants reported that provision of a better physical working environment would strongly motivate their level of motivation to perform even better in their teaching career. The physical working environment includes the classroom, teacher work rooms, teaching materials, resources as well as technology and internet access.

IP7 stated, "In order to have motivation for a better teaching performance, I need facilities such as a work room, internet, teaching materials and resources". IP1 stated that she is not against teaching new subjects, but she would like support through provision of teaching resources such as books. She said that some books are too expensive for her to buy for herself. IP8 talked about the number of students in each class. He said, "I am dissatisfied with big classes. This should be changed so that the quality of teaching could be improved." IP2 suggested that the university or department should provide lots of teaching material and resources, for example, for practical experiences for students to apply what they learn in the classroom. This support would be significantly helpful to her teaching. She said another resource could be having a guest speaker with lots of experience in the field.

\subsubsection{Recognition from the university}

Recognition is another potential motivating factor, mentioned by six interview participants. Recognition from the university could be afforded by providing a formal career structure and pathway, including ranks such as professor, associate professor, senior lecturer and so on.

Data from interview provided further insights. IP2, IP3, IP4 and IP7 believed that having a specific title or ranking would motivate them and also other teachers as it would reflect their effort and hard work. They also suggested that ranking and title should be given according to 
both years of experience and achievement. IP1 also said, "I think everyone loves teaching because of its value. Hence, giving specific status is a way to reflect teachers' effort. That also is what I want. As human beings, we need recognition and value.” In addition to ranking and title, IP2 suggested that the university or department provide official written appraisal letters. Verbal affirmation was not seen as permanent: "[A] written letter would strongly encourage me. It is a way of showing recognition to my hard work."

\subsubsection{Salary}

Salary was also seen as a potential motivating factor. In the interview data, five participants recommended increasing salary as a way to motivate them. Suggestions about how this could be done were made by the interview participants. IP8 said he wanted equality in the hourly wage across all departments. Teachers in some departments received a very small hourly wage compared to teachers in other departments even though the teachers were all in the same university. He said, "Of course, the more teachers work, the more wages they receive; however, teachers should at least be treated equally". IP4 said that the university should find a way to increase salary, as this would be a strong motivating factor. IP3 stated, "If teachers received enough salary, they would not need to work outside of the university". IP7 pointed out that salary should be kept in the line with inflation. Similarly, IP6 said:

Wages from private classes should be increased. It is still a bit low. I would like it to be increased. It motivates me because I do not need to work outside. Currently, because of low wages, I need to have extra teaching beside this university. The wages cannot cover my expenses.

\subsubsection{Management support and leadership}

Five interview participants referred to management support as a potential motivating factor. They felt that support was important to an effective work environment and would strongly influence their motivation. IP2 said:

I think that the teaching profession is a bit different from other professions. This profession absolutely requires willingness. There needs to be something from inside. I think support is crucial. I mean support by providing teaching material and resources. 
Besides management support, leaders with management power were also potential motivating factors. IP3 advised, "Leaders need to understand that, in order to construct effective teaching, what teachers basically need are teaching materials and resources, technology (websites where teachers can post their lessons), journal subscriptions, etc". He further claimed, "We want leaders who listen to us, who can lead us to improvement, who give us power in our own teaching". IP5 said:

I would like a more capable leader. I want him to be more open to enhancing and updating knowledge. I want him to understand that leadership at university is not like at high school. I think that in managing at university level, it is vital to have high vision. I do not want him to assume that all students that graduated from this university will only become teachers. In fact, we do not have only that mission. I want him to change his leadership attitude.

\subsubsection{Power}

Four interview participants mentioned that they would appreciate having some power and ownership through involvement in decision-making; participating in university decisions would provide a sense of belonging and ownership. IP8 expressed his desire to be involved in making decisions about adding new subjects or changing curriculum. IP4 suggested that university and management boost teachers' interest in their teaching by encouraging meetings among teachers of different departments, allowing opportunities to share and discuss together. He said, "We teach in the same university, so I want to get to know and keep in touch with each other teachers through seminars, get-together events or research. I would like to share ideas and experiences with other teachers between departments".

IP3 suggested:

I would like to be given more opportunities to participate, be given more power and ownership, not only in teaching but in some management within the university, allow teachers to get a sense of ownership. It is not like a few people were assigned by government to act like big bosses. It is not right... Having a look at the management at the university, they were assigned by the upper management. They only care about their upper boss, not the students or teachers who have no power over their positions. Therefore, teachers and students do not have much ownership or decision making. 


\subsubsection{Feedback}

Two kinds of feedback were referred to in the questionnaire: from the management and from the students. Four interview participants stated that feedback from both management and students would help improve their teaching. It would motivate them and show them what they have done, have achieved, or need to improve. IP1 and IP4 said that sometimes they did not know how good or poor their teaching has been and what they should do to improve their teaching. Hence, they needed feedback. IP3 suggested that he needed systematic evaluation or feedback in order to improve his teaching from either students or colleagues.

IP5 suggested there should be meetings weekly or monthly when teachers could get information about how their teaching is going, what is needed, what they are doing well. Meeting was seen as important. It would be a chance to provide feedback from lower to upper management or vice visa.

\subsubsection{Opportunities for undertaking research}

Opportunities for undertaking research described here is different from undertaking research (section 4.1.9 and 4.2.1.7). "Undertaking research" is internal desire of participants, while “opportunities for undertaking research" refers to an external chance which was provided to the participants. Opportunities for undertaking research were mentioned as a potential motivating factor by three interview participants. IP8 recommended that the university be more open to research and allow teachers to accept external sponsors or grants directly rather than having research opportunities provided only through the university administration. He wanted the university to strongly promote research. IP4 explained that the university should promote research because not all teachers want to only teach. He was interested in research. He explained that he did not mean that the university does not provide research opportunities at all, but the university should be more open and promote more research. He saw research as vital for university recognition. He said, “An internationally famous university is a university which is well known for research". IP4 concluded that the university should allocate financial support for research. Teachers could then conduct research and present it nationally or internationally, building recognition for the university. 


\subsubsection{Opportunities for upgrading knowledge and skills}

It is also noted that "opportunities for upgrading knowledge and skills" is different from "upgrading knowledge and skills". Opportunities for upgrading knowledge and skills was another potential motivating factor. Two participants recommended that while the university had some professional development programmes or teacher training, this support should be increased. IP1 said that she was interested in attending workshops or training or having the opportunity to share experiences with other teachers in different places. IP4 said, "Enhancing my knowledge and skills would highly motivate me in putting my best effort into my teaching practice".

\subsubsection{Students}

Two participants indicated that students motivate their teaching and performance. Hence, students should be properly selected for study at the university. For example, IP8 said,

Student performance has a great influence on my motivation. If the students are active, I am also enthusiastically active in my teaching. However, if they perform poorly, I am also so passive. I often observe when I teach any classes with active students, I am really physically exhausted... Hence, my main issue is students. If possible, university students should have enough qualification for university level. It is really difficult for me when I see students whose qualification is too low for their study.

\subsubsection{Cooperation within the university}

For two participants, cooperation within the university was a potential motivation force. IP5 stated:

I would like to see more cooperation between teachers. I would like them to participate in most of university activities. There is not much cooperation, not only within my department, but even within the university. For example, a subject in my department is almost the same as a subject in another different department. We have a completely different syllabus and teachers have never communicated at all. 
In summary, the findings reveal that there are current motivating factors and potential motivating factors in response to research question two. Generally, the major current motivating factors were associated with intrinsic motivation, whereas many of the potential motivating factors appear related to extrinsic motivations. The following section will describe the de-motivating factors that current tertiary teachers perceived.

\subsection{Research Question 3}

In this section, findings from the analysis of data relevant to research question 3: "How do tertiary teachers perceive de-motivating factors associated with their teaching profession?" are discussed. Eight factors were identified from the data. Each of these are described and discussed in the above order. As could possibly have been anticipated, there are some associations and similarities between potential motivating factors described in the last section and the de-motivating factors identified here.

\subsection{Lack of physical working environment}

Interview findings revealed that seven of the eight participants identified the lack of physical working environment as their main de-motivating factor. They were not satisfied with the facilities provided at the universities, in particular, especially the lack of teaching materials and resources. IP2 and IP4 said that their physical working environment was an obstacle and de-motivated them. They gave an example that there were not enough projectors to use. IP2 said, "I feel like teachers need to fight each other when they want to use one". IP4 explained, "I prepare power points to present in the class, but when I arrive at the department, there is not a projector to use". This finding is supported by a questionnaire statement asking "This university provides sufficient technology to support my teaching."; approximately 60 percent of the participants disagreed.

IP3, IP4 and IP6 also stated that a major obstacle to their teaching was lack of teaching materials and resources. They explained that some subjects they taught were very hard to resource. It was not easy for them to find those resources; for example foreign universities have journal subscription access, but their university did not. They added that technology at the university was still limited and the university or department was not able to afford new material or resources even though students needed them. IP3 stressed, "How can I update my teaching if we are so lacking in resources? Sometimes, some courses are really hard to find 
material and resources to teach. It is a big difficulty". IP8 mentioned that he had difficulties because there were not enough teaching classrooms for teachers within the university. IP6 reported that low support from her department is her de-motivating factor. She gave an example of the times she requested their support to buy teaching materials for her lesson. Sometimes they rejected her request; sometimes they provided her with low quality material, which she was not able to use to support her lesson.

\subsubsection{Low salary}

Although, salary was a reason for taking up the profession, low salary was also seen as a demotivating factor by five interview participants. The participants were not happy with the salary given. 24 questionnaire participants were not satisfied with the salary provided at the university. The majority of them disagreed with the statement "I feel I am being paid a fair amount for the work I do."

In the interview, IP2 stated, "I feel slightly dissatisfied with the salary. A teacher's salary is so low that sometimes it may not be even enough for petrol." Similarly, IP4 explained that salary was a problem for him. He said that it was impossible to focus on teaching if he had financial issues, although he was very willing to teach. He stated "While I am teaching, I also need to think about preparing my $\mathrm{CV}$ to apply for other part-time jobs or writing or so on. This must surely affect my teaching." In addition to the low salary, IP1 indicated that teachers did not receive a steady salary. She reported that she received a small permanent salary from the government 12 months a year. However, she also received extra salary paid by the hour for the extra hours of teaching. This extra salary was only for the hours she taught. It is not paid over 12 months. There is no teaching during the school vacation. So, no teaching, no salary. The lack of a steady salary made her feel dissatisfied.

\subsubsection{Lack of autonomy}

In the questionnaire, approximately two-third of the participants rated "involvement in decision making at the departmental level" and "involvement in decision making at the university level" as important to their motivation in teaching. Fifteen of the participants were dissatisfied within the departmental level; however, 24 were dissatisfied at the university level. 
Four interview participants reported that they were de-motivated because of lack of autonomy regarding subject teaching. They did not have the power to select the courses they teach. Courses were assigned to them. They felt pressured when they were given a new courses to teach. IP1 said that she used to feel this pressure. She stated: "If the management people are to teach, they are able to choose the courses themselves. However, I am not able to. This affects my motivation." IP6 said that because she was a new teacher, she was given new and difficult courses to teach. IP2 stated that she was sometimes given a new course, which requires her to do a lot more preparation and research. She said that it required not only a lot more of her effort, but also her time and money. Sometimes, she needed to buy books herself because the resources and books were old and could not be used in her teaching.

\subsubsection{De-motivating policy}

Five interview participants reported that strict policy is one of the de-motivating factors associated with their tertiary teaching profession. They said that not only university policy but also the government policy discouraged them. Those policies did not allow convenience and support in their teaching; instead they made teaching more difficult. IP5 stated that government policy was another de-motivating factor for her. She said that there is nowhere in the policy that refers to enhancing tertiary teachers' capacity. There are also no policies which focus on research or teacher professional development. She said that tertiary teachers need to be continually trained and encouraged to pursue further degrees such as a masters or a doctorate.

At the university level, IP2 was dissatisfied with the university policy that does not allow her to merge public and private students. As a result, she needed to teach twice on the same subject. It made her feel tired. If within a week she taught two sessions, she needed to teach the content four times. IP4 believed that the university policy is strict and complicated. For instance, when the department plans or requests teachers to do any activities, there is a strict control and complex procedure. IP8 stated that the administration is complicated in regard to hours of teaching. He said:

We teach according to credit but if my teaching is scheduled during a public holiday, there are no substitute hours. For example, there are 36 hours for a course, but the timetable of my teaching falls on holiday. I do not have 36 hours for my course, so I need to rush to finish without considering whether my students can catch up or not. 


\subsubsection{Lack of management support and poor leadership}

Lack of management and poor leadership is one of the de-motivating factors in tertiary teaching according to four interview participants. Questionnaire data showed that almost half of overall questionnaire participants disagreed that they received support from their department and the university.

In the interview, IP1 and IP5 complained about lack of management support in regard to teacher professional development or training. IP5 said that management seemed not to care about enhancing teachers' capacity. She would like to share her knowledge and experience in order to develop her department, but her leader often rejects her suggestions. It de-motivates her, making her feel tired or discouraged with her teaching. IP1 said that management should provide financial support for research or teacher professional development and training:

There are hundreds of staff and teachers, but is there any department or office which is developed for enhancing teachers' capacity? The university should create an office or institution in order to improve staff and teachers.

IP8 admitted that he became disgruntled with some leaders, who were unqualified to be leaders at tertiary level. Those leaders sometimes paid attention to politics, while forgetting that the mission of the university is to provide education and help students learn.

\subsubsection{Lack of cooperation within the university}

Besides lack of management support and poor leadership, another de-motivating factor is lack of cooperation within the university, according to three interview participants. IP3 observed that teachers have never had the opportunity to discuss experiences through workshops or seminars, or even to discuss information related to the development of the university. During school vacation, there was no final meeting reporting on teaching, university achievement, or the university's future plans. IP4 stated that he felt de-motivated when some of his colleagues commented negatively on what he was doing. He felt that there was no cooperation among teachers. He said that he spent time and effort to help the university and his department, but did not receive any care or support from colleagues. He felt discouraged from being present at the university when he saw that some teachers did not show up there. He said, "I feel that I too often come and stay at the department while those do not come are busy working outside of the university". IP5 also said cooperation between 
teachers is another obstacle for her. She said "For example, I expected students to have learned lessons from the previous semester, but the students did not. The teachers did not communicate with each other about what have been taught in the previous year. I sometimes needed to repeat lessons which I expected my students to had studied from previous courses again."

\subsubsection{Friendship networks}

Lack of open and contestable processes was another de-motivating factor. Four interview participants were very disheartened because they saw and felt they were not treated fairly. IP1 described that overuse of friendship networks reflected negatively on her motivation. She said "For example, a subject that I used to teach was given to other teachers who had a relationship with management. I have experienced this. I really dislike this and feel very unhappy". Similarly, IP5 and IP6 expressed that they were not happy when promotion occurred based on politics or relationships; qualified people who may be great leaders were not selected to because they were not from this or that party. They disliked it when there was unfair treatment or what they see as nepotism. IP8 also stated that there was sometimes inequality with allocation of teaching hours and courses because of a person's connections. He said "This is not right. I mean sometimes only those within a special network could be involved some particular work".

\subsubsection{Students' poor performance}

Two interview participants reported that student poor performance is another de-motivating factor. IP1 described that students' poor performance had a hugely negative influence on her motivation. She said that at tertiary level she did not want to push anyone, but she would like the students to understand their responsibility. She also said:

Before class, I have prepared lessons and felt enthusiastic, but if I saw students perform badly during classes, I did not feel like teaching. Because when I teach, I really hope that my students learn. When the students behave poorly, it shows that they disrespect me. Hence, I do not feel I want to teach.

IP2 also mentioned student performance as a de-motivating factor. She wanted students to be well-disciplined. She said that sometimes students disrespect her during class which made her slightly unhappy. 


\subsubsection{Lack of recognition}

In part II of the questionnaire, 32 participants agreed that there was really little chance for promotion on their job. Two- thirds of participants also disagreed with the statement "I feel my efforts are rewarded the way they should be". In other aspects of recognition in the questionnaire statement "I feel that my ideas are welcomed by the department's management," and "I feel that my ideas are welcomed by the university's management," 25 participants agreed with the former while 25 participants disagreed with the latter. This showed that participants were fairly happy with the level of recognition in their departments, but not the university. In part III of the questionnaire asking participants to rate the level of satisfaction at the university, 27 of 36 participants were not satisfied with recognition and rewards provided by the university. In addition, 26 of the participants were also dissatisfied with opportunities for promotion.

Lack of recognition from the university and department was a de-motivating factor mentioned by two interview participants. IP1 described that she was an active teacher but she had not received any encouragement from management. She did not always want only salary; she needed to feel appreciated and valued in response to her efforts. However, she felt that there was no difference in reaction to those who worked hard and those who did not. She therefore felt discouraged.

In conclusion, nine factors were reported by the participants which de-motivated them in their teaching profession. De-motivating factors identified in this study seem to be associated with extrinsic motivations. Teachers were not satisfied with external factors surrounding their teaching but these influenced their intrinsic motivation and enjoyment of their teaching. Some de-motivation factors were understandably found to be the same as potential motivating factors, such as lack of physical working environment, low salary, lack of management support and leadership. Factors which de-motivate could naturally be seen as desirous of change and vice versa, lack of change with regard to desired factors can become de-motivating.

Up to this point, the factors identified have been those which influence teachers' motivation in terms of their teaching performance. The following section reports on factors which may lead the teachers to leave or stay in their teaching profession. 


\subsection{Research Question 4}

This section will report on themes which emerged from questionnaires and interviews in response to Research Question 4: How do tertiary teachers perceive motivations that may lead them to leave or stay in their profession?

Participants were asked if they had ever thought of leaving. While a few responded in the affirmative, it was apparent that they had not seriously considered leaving. These participants also gave reasons for staying. At the time of interview all participants intended staying at least for the short term.

Of the eight interview participants, four stated that they had sometimes considered leaving the teaching profession (IP1, IP3, IP5 and IP8). However, there is none of them reported a strong desire to give up tertiary teaching positions. Each of them qualified their "yes" to the question "have you ever thought of leaving tertiary teaching profession?" differently. IP3 suggested he would return back to teaching again after some years working in new places. IP5 reported that she was considering leaving, but was waiting to see if there was any change with regard to her expectations of management. IP 8 said he has thought of leaving, but gave some factors which may motivate him to stay as well.

Four other interview participants (IP2, IP4, IP6, and IP7), who answered that they would stay in teaching, did not provide a strong commitment to stay only in teaching. IP2 said that she would continue teaching at the same time as taking up some other business which she is interested in. IP2 described that he had never thought of leaving teaching profession; however, extreme circumstances would require him to rethink. At the moment, he would stay in teaching. IP3 and IP7 also expressed similar feelings.

This section will report on the findings in response to the research question of perceptions of motivations that may lead teachers to leave or to stay in the teaching profession. Eight factors were found that may motivate teachers to leave. Some of these factors were similar to potential motivating factors and de-motivating factors identified in Section 4.2.2 and 4.3, showing that if these factors remain unresolved, they may become severe and may lead teachers to leave if the teachers meet other opportunities. Five main motivations were found which encouraged teachers to stay in the tertiary teaching profession. Motivations to stay are similar to current motivating factors identified in Section 4.2.1 and they are mostly intrinsic. 


\subsubsection{Factors that may motivate the teachers to leave teaching}

\subsubsection{Low salary}

According to the questionnaire findings, salary was the most common reason identified by participants that may make them leave the teaching profession. Fourteen out of 20 participants stated that they had thought of leaving tertiary teaching in response to an openended question in the questionnaire. They described the salary as low and not enough to support their living. In response to the statement "I feel that I am being paid a fair amount for the work I do", 30 participants disagreed with 10 of them strongly disagreeing. This means that low salary is a strong factor which may influence teachers to leave teaching profession.

One interview participant had thought about leaving the teaching profession because of low salary. IP8 said if he worked outside, he would get a double his current salary at the university.

\subsubsection{Lack of physical working environment}

The questionnaire findings revealed that seven participants suggested an inadequate physical working environment as one of the factors that may lead them to leave teaching.

In the interview findings, as described earlier in Section 4.3.1, an inadequate physical working environment was the main de-motivating factor for seven participants. This factor is also a reason that two interviewed participants were thinking of leaving the teaching profession. They found that their teaching was hard for them because there were not enough facilities such as the internet, journal subscription or teacher work rooms. They needed internet access or their own office room to work. They described that they felt frustrated and annoyed when they could not find where to sit or work.

\subsubsection{Lack of autonomy in subject teaching}

IP1 said that she thought of leaving teaching profession when she was given a new course to teach. She was overwhelmed when she could not find any material or resources to use to help her. She said "It was really time-consuming and hard to find anything to teach". Hence, she felt that this profession was very hard for her. 


\subsubsection{Lack of opportunities for undertaking research}

Two interview participants reported that few opportunities to conduct research at the university was the factor that may lead them to leave teaching. IP3 said that the university is not like other universities abroad which have practical research opportunities along with teaching. He mostly focused on teaching and did not have opportunities to conduct research which is practical experience that would enhance his teaching practice. He said the university was not able to afford more research opportunities, which encourages him to leave the university for a few years to work outside to meet his need. IP8 said that he wanted to be a researcher and wanted to create something new. However, he felt that he had very little opportunity for research. If there was another workplace with more research opportunity, he would want to a job there.

\subsubsection{Lack of opportunities for upgrading knowledge and skills}

IP3 explained that he thought of leaving teaching at the university for a while to develop his knowledge in a company or an organisation because he felt that he did not have new knowledge to teach his students after many years of teaching. He would like to have new experiences. He said "It does not make sense to me to always teach for my whole life. I would like to fill in the missing gap between theories in teaching and practical experience".

\subsubsection{Friendship networks}

Misuse of friendship networks is one reason an interview participant thought of leaving teaching. IP5 felt discouraged by people giving jobs to friends. She described that there was no harmony; teachers seemed to work separately in different groups and used peers for personal benefit. Teachers were not treated equally. For example, teachers who have close friendship network with higher-position people in the university or department were given more teaching hours which allowed them to receive more salary or were given easy subjects to teach. Teachers without useful contacts were provided with fewer hours of teaching and more difficult subjects. She stated "I can see the big gap between groups of those who work hard but receive less benefit and those who work less hard but receive more benefit". 


\subsubsection{Students' poor performance}

According to two interview participants, students' poor performance was a factor which may lead them to leaving their tertiary teaching profession. IP1 said that the times that she wants to give up teaching are mostly when students perform poorly with their learning. She stated that it is all right when they study hard and gain good results. She said she always tried her best effort to teach, but the students perform badly, she then felt absolutely exhausted. She concluded that "I do not know how I could help them". Similarly, IP6 said that she sometimes felt bored with teaching because of students. She stated that she tried hard in her teaching, but students were sometimes still not able to catch up. She said sometimes the students' ability at pursuing their undergraduate study is poor. This makes her feel tired and want to quit.

\subsubsection{Lack of management support and leadership}

Poor management support and leadership are factors which may lead IP5 to leave her teaching profession. She said that she did not receive any support from management or held no expectation that leaders were trying hard to improve the department: "The management usually rejects what we request. I mean it is bureaucracy. As the leader of department, s/he should not always follow what upper level managers' order. S/he should suggest that now the teachers should have this or that request. However, s/he does not do that and requests are usually rejected even before reporting to upper management."

\subsubsection{Motivations that may lead the teachers to stay in teaching}

\subsubsection{Personal interest in teaching}

There are two interview participants who said they will continue to stay in teaching because of their interest in it. IP1described that she felt this profession fitted her personality. Although there may be some factors which she is not satisfied with like salary, she still would like to continue teaching. In addition, IP3, who said he may leave teaching for a short period and would return to it, teaching was his aim.

\subsubsection{High social status}

The high social status of the teaching profession was reported as a factor which would motivate two interview participants to stay in teaching profession. IP1 stated that she really 
liked the profession because its value. The word "teacher "had huge meaning for her. Moreover, IP2 also said that teaching profession was highly valued which meant she would never think of leaving teaching profession.

\subsubsection{Upgrading knowledge and skills}

Upgrading knowledge and skills is another factor which motivates IP2 and IP4 to stay in the teaching profession. IP2 said that she likes to improve herself. Whenever she teaches, she also has opportunities to research and upgrade herself with up-to-date knowledge. In other words, the more she teaches, the more she can enhance her knowledge. She stated that she is always enthusiastic to learn something new.

\subsubsection{Characteristics of the profession}

IP2 and IP6 reported that they would stay in teaching profession because of the characteristics of this job. IP2 saw this profession an unpressured job. The teaching profession allowed her to meet different kinds of students and each class is different. Sometimes, she feels stressed, but when she goes into the classroom and sees the students, she feels much better and relaxes. IP6 said that this profession is not really hard and allows her some time to rest compared to other jobs.

\subsubsection{Helping younger generations}

Helping the younger generation is not only the reason for taking up teaching and the motivating factor in their teaching, but also a motivation that keeps two interview participants to think of staying in their teaching profession. IP7 said he would like to continue this profession because "I share what I know with my students. I have knowledge and I do not want to keep it to myself."

\subsection{Chapter summary}

In this chapter, the four research questions were addressed by the analysis of data gathered from interviews and questionnaires. In summary, tertiary teachers chose teaching as a profession for a range of reasons which were a mix of intrinsic and extrinsic motivations. However, factors which motivate teachers in their teaching practice and support them to stay in the profession seem to be mostly intrinsic motivations. On the other hand, potentially motivating and de-motivating factors appear linked and are more likely to be extrinsic. If 
solutions are not made to deal with de-motivating issues, teachers' intrinsic motivation may start to decrease and may lead them to leave the profession. Detailed discussion of the findings will be addressed in the next chapter. 


\section{CHAPTER 5 \\ DISCUSSION AND CONCLUSION}

This final chapter starts by summing up the key findings for the research questions. Then, it discusses the findings in relation to the literature. Limitations of the study are also indicated. Next, directions for further research are presented. It then offers various recommendations to tertiary education stakeholders who have the authority to improve teacher motivation in higher education institutions in Cambodia. The chapter ends with the reflections of the researcher on completion of the study and a final conclusion.

\subsection{Summary of the findings}

The findings to all four research questions are presented in Figure 1. Figure 1 shows the perceptions of participants as to the intrinsic and extrinsic motivation factors that supported their entry into the profession, support and constrain them to teach well while in the

profession and which encourage them to remain or leave the profession. Figure 1 is described and discussed in the following sections. 


\begin{tabular}{|c|c|c|c|c|c|}
\hline Research Question 1 & \multicolumn{2}{|c|}{ Research Question 2} & Research Question 3 & \multicolumn{2}{|c|}{ Research Question 4} \\
\hline Past (before teaching) & \multicolumn{3}{|c|}{ Present (while teaching) } & \multicolumn{2}{|c|}{ Future } \\
\hline & Current motivating factors & Potential motivating factors & $\begin{array}{l}\text { Current De-motivating } \\
\text { factors }\end{array}$ & Leaving tertiary teaching & Staying in teaching \\
\hline Intrinsic & Intrinsic & & & & Intrinsic \\
\hline $\begin{array}{l}\text { - Helping younger } \\
\text { generations and } \\
\text { contributing to society } \\
\text { - Personal interest in } \\
\text { teaching } \\
\text { - Upgrading knowledge } \\
\text { and skills } \\
\text { - Undertaking research }\end{array}$ & $\begin{array}{ll}\text { - } & \text { Helping younger } \\
\text { generations and } \\
\text { contributing to society } \\
\text { - } & \text { Devotion to teaching } \\
\text { - } & \text { Upgrading knowledge } \\
\text { and skills } \\
\text { - Undertaking research }\end{array}$ & & & & $\begin{array}{l}\text { - } \begin{array}{l}\text { Helping younger } \\
\text { generation }\end{array} \\
\text { - Personal interest in } \\
\text { teaching } \\
\text { - Upgrading knowledge and } \\
\text { skills }\end{array}$ \\
\hline Extrinsic & Extrinsic & Extrinsic & Extrinsic & Extrinsic & Extrinsic \\
\hline $\begin{array}{l}\text { - High social status } \\
\text { - Salary and living } \\
\text { standards of teachers } \\
\text { - } \text { Characteristics of the } \\
\text { profession } \\
\text { - People influence } \\
\text { - Circumstance }\end{array}$ & $\begin{array}{l}\text { High social status } \\
\text { - Characteristics of the } \\
\text { profession } \\
\text { Opportunities for further } \\
\text { study }\end{array}$ & $\begin{array}{l}\text { - Opportunities for } \\
\text { upgrading knowledge and } \\
\text { skills } \\
\text { - } \text { Salary } \\
\text { - } \text { Opportunities for } \\
\text { undertaking research } \\
\text { - Recognition from the } \\
\text { university } \\
\text { - Management support and } \\
\text { leadership } \\
\text { - Physical working } \\
\text { environment } \\
\text { - Power } \\
\text { - } \text { university } \\
\text { - Students } \\
\text { - Feedback }\end{array}$ & $\begin{array}{l}\text { - } \text { Low salary } \\
\text { - } \text { Lack of recognition } \\
\text { - } \quad \text { Lack of management } \\
\text { support and poor } \\
\text { leadership } \\
\text { - } \quad \text { Lack of physical working } \\
\text { environment } \\
\text { - Lack of autonomy } \\
\text { - } \quad \text { Lack of cooperation } \\
\text { within the university } \\
\text { - Students' poor } \\
\text { - } \quad \text { Ferformance } \\
\text { - } \quad \text { De-motivating policy }\end{array}$ & $\begin{array}{l}\text { - Lack of opportunities for } \\
\text { upgrading knowledge and } \\
\text { skills } \\
\text { - Low salary } \\
\text { - Lack of Opportunities for } \\
\text { undertaking research } \\
\text { - Lack of management } \\
\text { support and poor } \\
\text { leadership } \\
\text { - Lack of physical working } \\
\text { environment } \\
\text { - Lack of autonomy } \\
\text { - Student poor performance } \\
\text { - Friendship networks }\end{array}$ & $\begin{array}{l}\text { - High social status } \\
\text { - Characteristics of the } \\
\text { profession }\end{array}$ \\
\hline
\end{tabular}

Figure 1: Summary of the findings. Factors that positively motivate and support tertiary teachers are shown in green, those that de-motivate and do not support them to teach well are shown in red. 


\subsection{Motivations for becoming tertiary teachers}

The findings show both intrinsic and extrinsic motivation led the participants to become teachers. Perceptions of teaching as a stable and safe salary and valued career influenced both the teachers themselves and those who persuaded them to become tertiary teachers.

\subsubsection{Intrinsic motivation}

As in Figure 1, four intrinsic motivations emerged from the findings that encouraged tertiary teachers to choose the profession. The finding is similar to those of empirical studies that examined primary and high school teacher motivation in Cambodia. Benveniste, Marshall and Araujo (2008) found that 58 percent of the teachers who enter the teaching profession liked teaching as an activity, 21 percent followed their belief on the importance of education. Moreover, this current finding is supported by Nock and Bishop (2008) who identified that the most common reasons why teachers chose teaching as a career were a strong interest in the job, a wish to help Cambodia's development by improving education, and enjoyment of communication with children. Section 5.2.1.1 discusses one frequently-emerging factor that strongly motivates the tertiary teachers in this study to choose the teaching profession.

\subsubsection{Helping younger generations}

This theme emerged as the most common and important reason which draws these teachers into tertiary teaching as a career. Helping younger generations is an altruistic motivation as the motive is to serve people (Kyriacou \& Coulthard, 2000) and considered in this thesis as an intrinsic motivation. The belief that they are helping younger generations creates a sense of meaningful work and feeling of achievement among these teachers, categorising this factor as a motivator, according to Herzberg's two-factor theory (section 2.4.1.2). This finding is similar to those of some empirical studies of primary and high school teachers in Cambodia (Nock and Bishop, 2008; Uy, 2012). The participants in the present study commonly chose teaching as a career in order to help

others. This aspect of being responsible for supporting future generations may be influenced by cultural factors. In Cambodian society, people respect teachers as role models for others; thus, if teachers do well, people admire them, but if their students do not do well, they would be blamed. These societal beliefs about the influence of teachers may shape teachers' beliefs about the significance of the teaching role in helping others. 
In this study, it can be concluded that being a teacher was not seen so much as a career to earn a living, but more one to help others; teachers in this study commonly held a strong sense that helping the next generation was very important for their society.

\subsubsection{Extrinsic motivation}

In addition to intrinsic motivations, tertiary teachers chose teaching because of external factors. According to Maslow, people need status. Teaching was the top choice as a profession of the majority of teachers (96 percent) found in a study by Benveniste, Marshall and Araujo (2008), indicating the cultural respect for the teaching profession that exists in Cambodia. It can be said that this high social status also motivated tertiary teachers to choose teaching as a career. Moreover, the influence of people on their career choice is in common with findings of two studies conducted with Cambodian primary school teachers. These teachers also chose teaching because of the influence of people such as their parents or previous teachers (Nock \& Bishop, 2008; Uy, 2012). As suggested above, status and security, as well as respect and the perceived value of teaching may also be an element influencing the advice of these people.

\subsection{Current tertiary teaching: Motivating and de-motivating factors}

Current motivating factors which encourage participants to teach well are similarly a mixture of both intrinsic and extrinsic factors. For example, helping younger generation and devotion to teaching are intrinsic, whereas high social status and the characteristics of the profession are extrinsic. Figure 1 shows that most of current tertiary teacher motivations are the same as those motivations which led to them to take up teaching. Only one current motivating factor "opportunities for further study" was not mentioned as a reason for becoming tertiary teachers.

According to Figure 1, many of de-motivating factors were similar to those of potential motivating factors which the teachers suggest should be present in order to motivate them to put more effort into their teaching. Those in common are: salary, recognition, management support and leadership, physical working environment, cooperation with the university, and power or autonomy. In addition to these factors, participants also suggested some other potential motivating factors named as opportunities for upgrading knowledge and skills, opportunities for undertaking research and feedback. Friendship 
network and de-motivating policy are the additional de-motivating factors. The most common potential motivating and de-motivating factors will be discussed in depth below.

\subsubsection{Intrinsic motivation}

According to the findings, it is noted that intrinsic factors which drove them into teaching are also the same as those which sustain their motivation in their current teaching. This can be explained in that because intrinsic motivations are imposed internally, they have a deep and long-term effect on tertiary teachers. Moreover, the intrinsic motivations found in this study acts as motivators, which, based on Herzberg's theory (1959), have a longterm positive influence. These factors support tertiary teachers' attitude to their work and encourage them to work hard. That is why those intrinsic motivations which motivated them to take up teaching continue to emerge as their motivating factors in their present teaching.

As discussed in section 5.2.1.1, helping younger generations remains as a strong motivating factor for these tertiary teachers. This finding is not supported by many previous empirical works. Only one study on motivations of teachers at a Hungarian university found that a highly motivating intrinsic factor supporting teaching was seeing the students' improvement which helped teachers see the importance of their teaching and feel that they were responsible for imparting knowledge to their students (Menyhart, 2008). It can be argued that a willing attitude to help younger generations through transferring knowledge was not common in other countries. This attitude is, however, common in Cambodian teachers. For example, Pou (2012), a lecturer at a university in Cambodia, wrote in his reflection article that 'the key to the future is in the hands of the students in Cambodia... They deserve the best education...I want to do my part. I want to give and share something priceless, the gift of learning. I want to fulfil my social responsibility to assist the young generation become responsible learners and develop their potential...in making a lasting contribution to Cambodia's future." Such attitudes and motivations may be related to Cambodia's history and stage of development.

\subsubsection{Extrinsic motivation}

The finding of Research questions 2 and 3 showed that extrinsic motivation accounted for the majority of complaints from teachers such as low salary, lack of recognition, lack of autonomy so on and so forth. However, some of the factors that led participants into 
teaching did not continue to meet their expectations. These factors can be seen in the list of potential motivating factors and current de-motivating factors. Herzberg's theory explains that hygiene factors which are extrinsic will cause the tertiary teachers to become de-motivated if those factors are not present (1959).

\subsubsection{Potential motivating and current de-motivating factors}

It can be noticed from Figure 1 that many of the potential motivating and current demotivating factors are similar. Common potential motivating and current de-motivating are discussed next.

\subsubsection{Salary}

The study found that in addition to intrinsic motivators, extrinsic factors also motivated these people to choose tertiary teaching as a career, in particular, salary. However, inadequate salary was also a de-motivation in their teaching career and could be a motivation leading them to leave the profession if the issue is not addressed. While the prospect of a steady salary encouraged them into teaching, the need to supplement the basic salary with private teaching was sometimes de-motivating. Based on Herzberg's hygiene factors, lack of sufficient salary means that teachers will be dissatisfied in their work. Salary is a basic physical need in Maslow's theory and must be fulfilled if teachers are to remain motivated. According to the findings, the participants revealed that it was likely that they may not focus on their teaching well if they are facing financial issues. Similarly mixed motivations concerning salary are found in the literature. Kiziltepe (2008) and Toker found that Turkish tertiary teachers considered their salary to be quite low and considered this as a de-motivation factor. In Uganda, Ssesanga and Garrett (2005) showed that inadequate and irregular salary was the most frequently mentioned factor which contributed to academic dissatisfaction. Resheed et al., (2010) revealed that compensation was a strong motivator for teachers in a university in Pakistan, and teachers were not satisfied with their current compensation. Rowley (1996) also found that financial rewards were a strong motivator for tertiary teachers in the United Kingdom. In contrast, a study in Argentina by Pinto and Pulido (1997) stated that financial reward was the least common motivator for teachers.

Compensation of teachers is believed to be critical in attracting teachers to and keeping them in the profession. The pay may play as an incentive and reward to enhance the 
quality of the teaching pool and teaching force as well as to reduce teacher attrition (Abeysekera \& Abeysekera, 2012). It might be understood that stronger candidates would be attracted to teaching as a career and more effective teachers might be retained if teachers could earn higher pay both on entry and over time. According to Johnson, Berg, and Donaldson (2005), pay is considered as an important factor in teachers' initial career choices. Moreover, Loeb and Reininger (2004, p. 39) "teachers respond to wages and are more likely to choose to teach when the starting teacher wages are high relative to wages in other occupations." In this study, salary was a factor which attracted teachers into tertiary teaching; however, low salary became a de-motivation. It may be argued that salary was considered attractive for the beginning teachers, but after they have been teaching and gained many years of experience, the expectations of the increased salary was higher. In addition, Rany, Zain, and Jamil (2012a) suggested that the increase of private higher education institutions in Cambodia and low salaries in the public sector have led to the loss of more and more government university lecturers to private institutions that offer well-paid salaries.

\subsubsection{Physical working environment}

The findings revealed that the physical work environment was a strong de-motivation factor and sufficient physical work environment would act as a potential motivating factor for these teachers. This finding is similar to those of Morgan (1974), Rowley (1996) and Menyhart (2008). Their studies described how lack of resources and equipment caused teachers to feel de-motivated in their teaching. The inadequacy of facilities has always been a source of frustration and often de-motivating for teachers (Chindanya, 2002). Being effective in the classroom was very important for all teachers, but if working conditions hindered teachers to achieve intrinsic rewards in their teaching, they might leave the classroom or psychologically leave the profession. Theories reviewed in Chapter 2 provide explanations for these findings. Vroom's expectancy theory (Section 2.4.2.2) hypothesizes that motivation is a force within a person. Expectancy is a perceived relationship between action and its direct outcomes. In educational contexts, teachers work effectively when they expect their efforts to produce good outcomes. So if they perceive physical work facilities as lacking in relation to the teaching to be accomplished, they may be de-motivated through thinking that it may be impossible to accomplish the task. In Maslow's hierarchy of needs theory (Section 2.4.1.1), competence is described as an important esteem need. Teachers who see their competence diminished by lack of 
resources will be de-motivated and unfulfilled. Teachers need to experience a sense of competence. Ensuring that resources are adequate for teachers can be seen as an important role of management if teachers are to remain motivated and accomplish their teaching goals.

\subsubsection{Management support and leadership}

The study found that lack of management support and poor leadership is currently demotivating tertiary teachers, while supportive management and leadership would be a potential motivating factor to make the teachers perform better in their teaching. When management was perceived as not being supportive, teachers were in danger of becoming de-motivated. The leadership could be seen as failing to provide for the social and esteem needs of teachers, according to Maslow's theory (Maslow, 1943). At the social level Mills (1987) comments that staff need someone to listen to their problems. Leaders need to provide support and leadership by giving teachers feedback on their performance. Many of the teachers in this study did not feel their efforts were recognised and appreciated. According to Herzberg (1968), poor leadership also contribute dissatifactions such as uncoordinated planning, poor policy, and poor supervision (section 2.4.1.2).

Vroom's theory (Vroom, 1964) (Section 2.4.2.2) indicates that educational managers and leaders should allocate praise, recognition, some privileges, and opportunities for growth as well as criticism, disapproval and tedious tasks. In this way they can influence teachers' expectancies and their perceived instrumentalities, and thus motivate them to achieve desired outcomes or goals. Under unsupportive and poor leadership all these do not happen. This means teachers have to motivate themselves.

\subsubsection{Feedback}

Related to the above section is the lack of feedback demonstrated in this study as causing some teachers to feel de-motivated in their teaching. The participants stated feedback as their potential motivating factor which would encourage them to put more effort into their teaching. This is supported by Locke's goal setting theory (Locke \& Latham, 1990). Locke and Latham (1990) determined feedback as one condition to motivate the individuals to produce a high performance in their job. As described above, Maslow (1943) and Herzberg (1968) affirm that the need for recognition is a great motivator which can be affected by means of feedback. According to Daniels (as cited in 
Chindanya, 2002, p. 113) feedback is "information about performance that allows an individual to adjust his or her performance," and without feedback there is no learning. Feldman and Paulsen (1999) also identify that in order to have a supportive teaching culture, feedback is important. Feedback can come from many sources such as colleagues, leaders, students, and teachers themselves (use of self-rating forms and selfreports). Such feedback helps to address the needs of faculty for self-determination and excellence in teaching, and provides opportunities for them to learn and achieve, informing and supporting them in efforts to improve their instruction.

\subsubsection{Friendship networks}

Friendship networks was found as a de-motivation which also may lead teachers to leave their career. In the context of the equity theory (Adams, 1965), an inequity is perceived when management is viewed as favouring some members of staff when it comes to the allocation/distribution of rewards. On the feeling that an inequity exists, one is demotivated (Bush and West-Burnham, 1994). According to Maslow's hierarchy of needs theory (Section 2.4.1.1), showing friendship network or discrimination threatens the security and safety needs of employee. When this happens motivation is depressed. In accordance with Herzberg's Motivator-Hygiene theory (Herzberg, 1968) (Section 2.4.1.2), poor supervisory practices such as favouritism constitute dissatisfiers that must be removed in order for motivators to effectively come into play. The educational leaders may need to identify and consider such practices if they are creating perceptions of inequity.

\subsubsection{Recognition}

According to the findings, teachers consider recognition a potential motivating factor which helps them perform their best effort in teaching, while lack of recognition causes the teachers to feel de-motivated. In the context of Vroom's expectancy theory (Vroom, 1964), the increase of motivation to engage in an activity is a combination of one's expectation that the effort will result in a particular outcome and the perceived value of that outcome. Thus if teachers see their effort put into their teaching has been rewarded and recognised, they will demonstrate an increase in their performance. On the other hand, if they perceive that their effort is negatively noticed, their performance will decrease. Herzberg (1968) listed recognition as a strong motivator. Maslow (1943) 
regarded esteem as an important need which has great motivational potency. Teachers need to be valued, and this calls for recognition of good work done.

\subsection{Future: Motivations for remaining and leaving tertiary teaching}

The findings showed that motivations which keep teachers to stay in their teaching consist of both intrinsic and extrinsic factors. It is noticeable that all the intrinsic factors are the same as those intrinsic factors which led tertiary teachers to choose teaching profession and which are currently motivating them to teach well. On the other hand, factors which may lead tertiary teachers to leave their teaching profession are all extrinsic. According to George and Sabapathy (2011), although extrinsic factors are outside of the control of individual they are often in the control of management. It can be argued that extrinsic motivators can be fixable by the management. It is important to note that while intrinsic factors motivated the teachers in this study to become and remain teachers, there were several extrinsic factors identified which have potential to become de-motivating and increase desire to leave if not addressed. This means that if the extrinsic motivations remain unaddressed, there is a potential threat of undermining the intrinsic values of tertiary teachers. This can be argued from Maslow's (1943) hierarchy of needs of higher-order and lower-order needs. According to Maslow, in order to achieve higher-order needs, lower order needs which are extrinsically provided need to be met. In addition, Herzberg's (1968) theory indicates that if hygiene factors are not present, dissatisfaction increases and motivators that support teachers to remain in the profession may have less influence. Hence, management plays a crucial role in maintaining teachers' intrinsic motivation through improving extrinsic motivations. Recommendations to management drawn from this study will be discussed in the next section.

\subsection{Limitations, implications and recommendations}

\subsubsection{Limitations of the study}

This study is limited in many important ways. Firstly, this is a case study so cannot be generalised, although information has been provided that enables the reader to identify the degree to which results of this study can be applied to their situation. Another limitation of this study is that it was conducted with a small sample due to the time and size constraints of a masters thesis and also because of the university vacation period that occurred during the time available for data collection. Thirdly, the study did not explore 
the perceptions of those tertiary teachers who have already stopped teaching; thus, the indepth information about teacher attrition is not known. Also, participants are currently teaching. Research Question 1 demanded that current teachers look back at their reasons for joining the profession. The accuracy of their hindsight cannot be guaranteed. Their current views may influence their retrospective interpretation.

\subsubsection{Implications for further research}

As mentioned in the methodology chapter, this exploratory case study can be used to "develop pertinent hypotheses and propositions for further inquiry" (Yin, 2003, p. 6). There is great potential for this study to inform research in related areas. This study was conducted with the hope that it can serve as a basis for further research which will lead to improvement of better situations where tertiary teachers in Cambodian higher education will be as highly motivated as possible. In Cambodia there has been no previous research to investigate the reasons why tertiary teachers choose teaching as a career and remain in the profession. These results have suggested factors which may be useful to prospective researchers to investigate more widely and in greater depth. The change over time of teacher motivation and de-motivation factors associated with the teaching profession in Cambodian higher education institutions could also be worthy of study. In addition, the focus of further research could be on investigating in greater depth the factors which have the greatest actual influence on teacher motivation.

Because the number of participants in this study was limited to two departments due to time constraints and the vacation period, it is recommended that further research with more participants from various departments be carried out to provide different views. Also, the study was conducted to identify the factors that caused teachers to opt for teaching career and stay in it, but it was done with only one university; thus, there should be more universities included in future investigations. Furthermore, future research should be conducted both in the rural provinces and the city to embrace different views from teachers in different regions. Possibly, it should also be done with private universities to compare responses from public university teachers and those from private university teachers. Moreover, future research should also seek for the reasons as to why some teachers leave the profession. Such research would enable comparison to be made between those teachers who remain in the teaching force and those who have already left teaching, to develop greater understanding of teacher retention and attrition. 


\subsubsection{Recommendations}

Although future research is implicated for this study, some recommendations can be made for consideration by providers of higher education in Cambodia. On further reflection of Figure 1, it is important and interesting to note that the majority of the factors which would improve tertiary teacher motivations and support them to perform better, and which may prevent them from leaving their teaching if those factors are addressed, are within the control of the university management. It is clear that university management plays an important role in motivating teachers. They may wish to consider whether the needs of tertiary teachers are being met.

- Remuneration. In this context, while the university cannot control the salary provided by the government, the university can re-adjust the system of payment on private extra teaching hours as the university is partly self-funded from feepaying services. Teachers suggested that the university should increase the amount of money paid per teaching-hour. Increasing salaries is the most urgent issue to be addressed. Teachers would then be more focused on teaching at the university without having to take up part-time jobs outside of the university. To some extent, this would contribute to the increase of teacher productivity at the university.

- The friendship network culture. Teachers need to perceive that everyone is treated fairly. They would be better motivated if they perceive an individual's input is rewarded equally. If benefits are shared equally, teachers may feel more satisfied.

- Decentralisation of decision making. Findings suggest that teachers may need more influence in decision making. This may create a greater sense of belonging. As teachers are the ones who implement university policy, a greater sense of involvement in decision making would smooth implementation processes also.

- Physical work environment. This most commonly highlighted factor impacts on teachers' ability to demonstrate their competence. It is recommended that the university consider ways that the physical work environment could be improved, such as teaching materials, resources, internet, and facilities. 
- Feedback. Ways that teachers can be provided with feedback in order to guide their behaviour and improve performance should be considered.

- Recognition. In order to encourage teachers to stay, they need to feel that their work is appreciated. Recognition is significant. Recognition can be given by giving ranking, a reward, or official written appreciation letter organised by the university.

- Student performance. Although students' poor performance is beyond the control of the university, the way students are were selected for admission, could be considered. Setting criteria which enable recruitment of students who are likely to show adequate competence to pursue their chosen disciplines could influence teachers' perceptions on this issue.

- Professional development and research opportunities. It is recommended that university considers creating centre for teachers' professional development where teachers could improve their qualification, skills, and research. Allowing funds for research, seminars, and workshops would support teachers' motivation. Supporting the cooperation of research projects in collaboration with external institutions and other departments may also allow more opportunities in this area.

These recommendations are supported by the eight characteristics of supportive teaching culture identified by Feldman and Paulsen (1999) which were believed to "constitute a context that promotes the availability of various forms of informative feedback about an individual's teaching effectiveness, which in turn stimulates teachers' motivation for instructional excellence" (p.71).

1. High-level administrative commitment and support

2. Faculty involvement, shared values and a sense of ownership: allow for involvement of faculty in every aspect of planning and implementing activities.

3. A broader definition of scholarship

4. A teaching demonstration or pedagogical colloquium as part of the hiring process

5. Frequent interaction, collaboration and community among faculty: This allow teachers to talk about their teaching 
6. A faculty development program or campus teaching center: such as individual consultations, departmental consultation, workshops, seminars, conference, annual award programs, teaching assistant training program, material on teaching development, and institutional participation in grants and research on teaching and faculty development

7. Supportive and effective department chairs: The chairs is important to create a culture that value teaching

8. Connecting rigorous evaluation of teaching to tenure and promotion decisions: Evaluation can be from peer and students.

With the exception of the fourth point, which was not a focus for this study, these points relate strongly to the findings and implications described above.

\subsection{Reflections of the researcher}

Particularly, as being very new to the conducting of such a study, the researcher has learned much about the features of the research topic, which was broader than she expected, and which addressed issues specific to her own situation. Importantly the researcher developed understanding of the process of doing research although there were some limitations along the way. The researcher was initially concerned that there might be difficulty in researching tertiary teacher motivation in Cambodia. The assumption was that Cambodian teachers may not feel comfortable speaking about their educational culture and about their motivational difficulties with their teaching or management. This proved the opposite as Cambodian teachers participated in this study, providing in-depth data looking at the motivation they experience at their universities. The teachers were very interested in speaking their minds and providing ample information for the study of their motivation. The researcher learned about many issues related to difficulties and motivation amongst teachers.

\subsection{Concluding remarks}

The findings revealed that teachers were both influenced by intrinsic and extrinsic factors in choosing their teaching career. Many of the intrinsic and extrinsic factors motivating them to take up teaching remain as motivations in their current teaching, and lead them to stay in teaching. Extrinsic motivations account for de-motivations and also have the 
potential to lead teachers to leave their profession. There is a potential that intrinsic motivations will be undermined if these extrinsic factors are not addressed. Extrinsic factors are within the control of management. The role then of an educational administrator or leader is to pay attention to extrinsic factors in order to create an environment in which a teacher's intrinsic motivation may be released to guide and sustain that motivation.

Teachers play a key role in higher education institutions. They are key resources in achieving the goals and objectives of such institutions. They are strong determinants in the provision of quality teaching to students. This study has explored tertiary teacher motivations for choosing and remaining in their teaching profession, while at the same also examining the motivating and de-motivating factors associated with their careers. It is hoped that it can serve as the basis for further research in order to improve situations for tertiary teachers that will enable them to be more highly motivated and productive in their teaching careers. 


\section{References}

Abdul Cader, A. (2012). Motivational issues of faculty in Saudi Arabia (Unpublished PhD dissertation). Walden University, United States.

Abeysekera, A., \& Abeysekera, V. (2012). Motivating the construction academic: a conceptual study. In Proceedings, World Construction Conference 2012: Global Challenges in Construction Industry (pp. 1-13). Ceylon Institute of Builders (CIOB).

Adams, S. J. (1965). Inequity in Social Exchange. In L. Berkowitz (Ed.), Advances in Experimental Social Psychology, Vol. 2 (pp. 267-99). New York: Academic Press.

Bahrami, M. A., Ezzatabadi, M. R., Jamali, E., Tafti, A. D., Tehrani, G. A., \& Ardakani, S. E. (2012). Job motivation factors: a case study of an Iranian Medical University. Global Advanced Research Journal of Management and Business Studies, 1(10), 345-352.

Bell, J. (1993). Doing your research project: A guide for first-time researchers in education and social science. Buckingham: Open University Press.

Benveniste, L., Marshall, J., \& Araujo, M. C. (2008). Teaching in Cambodia.. Cambodia: The World Bank and Ministry of Education, Youth and Sport.

Bess, J. L. (1977). The motivation to teach. Journal of Higher Education, 68(3), 243-258.

Bouma, G. D. (1998). The research process (3rd ed.). Melbourne: Oxford University Press.

Braun, V., \& Clarke, V. (2006). Using thematic analysis in psychology. Qualitative Research in Psychology, 3(2), 77-101.

Bryman, A. (2008). Of methods and methodology. Qualitative Research in Organizations and Management: An International Journal, 3(2), 159-168.

Bush, T., \& West-Burnham, J. (1994). The principles of educational management. Britain: Pearson Education.

Chet, C. (2006). Cambodia: Overview of higher education developments. Higher Education in South-East Asia (pp.13-31). Bangkok: UNESCO Bangkok. 
Chindanya, A. (2002). Motivating professional staff as a managerial task at a higher education institution (Unpublished Masters Dissertation). University of South Africa, South Africa.

Cohen, L., Manion, L., \& Morrison, K. (2007). Research methods in education (6 ${ }^{\text {th }}$ ed.). Abingdon: Routledge.

Creswell, J. W. (2007). Qualitative inquiry and research design: Choosing among five approaches. United States of America: Sage Publications, Inc.

Creswell, J. W., \& Miller, D. L. (2000). Determining validity in qualitative inquiry. Theory into Practice, 39(3), 124-130.

Davidson, C., \& Tolich, M. (1999). Social science research in New Zealand (Eds). Auckland: Pearson Education.

Davidson, C., \& Tolich, M. (2003). Competing traditions. In C. Davidson \& M. Tolich (Eds.) Social science research in New Zealand: Many paths to understanding (2nd ed.) (pp. 23-38). Auckland: Pearson Education.

Denscombe, M. (1998). The good research guide: For small-scale social research projects. Buckingham: Open University Press.

Denscombe, M. (2010). The good research guide: For small-scale social research projects $\left(3^{\text {rd }}\right.$ ed.). Berkshire: Open University Press.

Denzin, N. K., \& Lincoln, Y. K. (2000). Handbook of qualitative research ( $2^{\text {nd }}$ ed.). Thousand Oaks, CA: Sage Publications.

Dörnyei, Z., \& Ushioda, E. (2001). Teaching and researching motivation. Essex, UK: Pearson Education Limited.

Eccles, J. S., \& Wigfield, A. (2002). Motivational beliefs, values, and goals. Annual Review of Psychology, 53(1), 109-132.

Feldman, K. A., \& Paulsen, M. B. (1999). Faculty motivation: The role of a supportive teaching culture. New Directions for Teaching and Learning, 1999(78), 69-78.

Gay, L. R., Mills, G., \& Airasian, P. W. (2009). Educational research: Competencies for analysis and interpretation. New Jersey: Pearson. 
George, L. \& Sabapathy, T. (2011). Work motivation of teachers: Relationship with organizational commitment. Canadian Social Science, 7(1), 90-99.

Grubisic, D., \& Goic, S. (2003). Demotivation factors research study in a manufacturing company in Croatia. SEER-South-East Europe Review for Labour and Social Affairs, (01+ 02), 153-178.

Hargreaves, A. (1998). The emotional practice of teaching. Teaching and Teacher Education, 14(8), 835-854.

Herzberg, F. (1968). One more time: How do you motivate employees? Harvard Business Review, 46 (1), 53-62.

Herzberg, F., Mausner, B., \& Snyderman, B. (1959). The motivation to work. New York: John Wiley \& Sons, Inc.,.

Innes-Brown, M. (2006). Higher education, Cambodia. Australian Education International, National Office of Overseas Skills Recognition, Department of Education, Science and Training. Canberra: DEST.

Johnson, B., \& Christensen, L. (2008). Educational research: Quantitative, qualitative, and mixed approaches $\left(3^{\text {rd }}\right.$ ed.). Thousand Oaks, CA: Sage Publications.

Johnson, S. M., Berg, J. H., \& Donaldson, M. L. (2005). Who stays in teaching and why?: A review of the literature on teacher retention. Cambridge, MA: Harvard Graduate School of Education. Retrieved December 25, 2012 from http://assets.aarp.org/www.aarp.org_/articles/NRTA/Harvard_report.pdf

Kiziltepe, Z. (2008). Motivation and demotivation of university teachers. Teachers and Teaching: Theory and Practice, 14(5-6), 515-530.

Kupers, W. (2001). A phenomenology of embodied passion and the demotivational realities of organisations. Paper presented at CMS 2001, Manchester. Retrieved December 27, 2012 from http://www.mngt.waikato.ac.nz/ejrot/cmsconference/2001/Papers/Passion\%20for\% 20Organising/Kupers.pdf

Kyriacou, C., \& Coulthard, M. (2000). Undergraduates' views of teaching as a career choice. Journal of Education for Teaching: International research and pedagogy, 26(2), 117-126.

Lai, E. R. (2011). Motivation: A Literature Review. Retrieved November 30, 2012 from https://pearsonassessments.com/hai/images/tmrs/Motivation_Review_final.pdf 
Lankford, H., Loeb, S., \& Wyckoff, J. (2002). Teacher sorting and the plight of urban schools: A descriptive analysis. Educational Evaluation and Policy Analysis, 24(1), $37-62$.

Lichtman, M. (2010). Qualitative research in education: A user's guide. Los Angeles: Sage Publications, Inc.

Locke, E. A. \& Latham, G. P. (1990). A theory of goal setting \& task performance. Englewood Cliffs, N. J.: Prentice Hall.

Locke, E. A., \& Latham, G. P. (2006). New directions in goal-setting theory. Current Directions in Psychological Science, 15(5), 265-268.

Lortie, D, C. (1975). School teacher: A sociological study. Chicago: University of Chicago Press.

Maslow, A. H. (1943). A theory of human motivation. Psychological Review, 50(4), 370396.

McLaughlin, C. (2005). Toward a theory of faithfulness: An exploratory study of the motivational factors related to human capital retention in the Christian school (Unpublished PhD dissertation). Capella University, United States.

McShane, S. L. \& Von Glinow, M. A. (2003). Organizational Behaviour. New York: McGraw-Hill.

McShane, S., \& Von Glinow, M. (2003). Organizational behaviour: Emerging realities for the workplace revolution (2nd ed.). New York: McGraw-Hill Higher Education.

Menyhárt, A. (2008). Teachers or lecturers? The motivational profile of university teachers of English. WoPaLP, 2, 119-137.

Merriam, S. B. (1998). Qualitative research and case study applications in education. San Francisco: Jossey-Bass.

Merriam, S. B. (2002). Assessing and evaluating qualitative research. Qualitative research in practice: Examples for discussion and analysis, (pp. 18-33). San Francisco: Jossey-Bass.

Miles, M. B. \& Huberman, A. M. (1994). Qualitative Data Analysis: An expanded sourcebook. Thousand Oaks, CA: Sage Publications. 
Mills, H. (1987). Motivating your staff to excellence: Some considerations. NASSP Bulletin, 71(503), 37-40.

Miner, J. B. (2005). Organisational behaviour I: Essential theories of motivation and leadership. The United States of America: M.E. Sharpe, Inc.

Ministry of Education, Youth, and Sports. (2009). National education congress report. Cambodia. Retrieved August 24, 2012 from http://www.moeys.gov.kh/DownLoads/Publications/National Education Congress Summary Report.pdf.

Miskel, C. G. (1982). Motivation in educational organizations. Educational Administration Quarterly, 18(3), 65-88.

Molander, G. (1996). Human resources at work. Lund: Chartwell-Bratt.

Morgan, T. D. (1974). A study of teacher motivation in a public California university (Published Ed. D. dissertation). University of Southern California, United States.

Morra, L. \& Friedlander, A. C. (1999). Case Study Evaluations, OED (Operations Evaluation Department) Working Paper Series No. 2, May, World Bank.

Mullins, L. J. (1999). Management and organizational behaviour (5 ${ }^{\text {th }}$ ed). London: Financial Times Prentice Hall.

Naseer ud Din, M. (2008). A study of motivation techniques used by heads of institutions of higher education and their impact on the performance of teachers (Unpublished master thesis). University of Arid Agriculture, Pakistan.

National Institute of Statistics. (2010). Cambodian demographic and health survey 2010. Phnom Penh: Ministry of Planning.

Neuman, W. L. (2000). Social research methods: Qualitative and quantitative approaches. Boston: Allyn \& Bacon.

Neves de Jesus, S., \& Lens, W. (2005). An integrated model for the study of teacher motivation. Applied Psychology, 54(1), 119-134.

NGO Education Partnership. (2012). Assessing the impact of incentives on teacher motivation. Phnom Penh: NGO Education Partnership. 
Nock, S., \& Bishop, R. (2008). Teaching matters: A policy report on the motivation and morale of teachers in Cambodia. Phnom Penh: NGO Education Partnership, and VSO.

Oregon School Boards Association. (2009). Motivating teachers to improve instruction. Retrieved March 27, 2012 from http://www.osba.org/Resources/Article/Employee_Management/Motivating_Teach ers_to_Improve_Instruction.aspx

Patton, M. Q. (2002). Qualitative research and evaluation methods (3rd ed.). London: Sage.

Pinto, G., \& Pulido, E. (1997). Motivation of faculty members at a Latin American university: A case study. European Journal of Engineering Education, 22(4), 421426.

Pit, C., \& Ford, D. (2004). Cambodian Higher Education: Mixed Visions In P. G. A. \& T. Umakoshi (Ed.), Asian universities: Historical perspectives and contemporary challenges (pp. 333-362). Baltimore and London: The Johns Hopkins University Press.

Poppleton, P. (1989). Rewards and values in secondary teachers' perceptions of their job satisfaction. Research Papers in Education, 4(3), 71-94.

Porter, L., \& Steers, R. (1973). Organizational work and personal factors in employee turnover and absenteeism. Psychological Bulletin, 80, 151-176.

Pou, S. (2012, January 4th). Case Study on opportunities and challenges of higher education in Cambodia [Campropost]. Retrieved from http://campropost.org/2012/01/04/case-study-on-opportunities-and-challenges-ofhigher-education-in-cambodia.html.

Rany, R., Zain, A. N. M., \& Jamil, H. (2012a). Establishment of Institutional Policies for Enhancing Education Quality in Cambodian Universities. International Journal of Higher Education, 1(1), 112-127.

Rany, S., Zain, A. N. M., \& Jamil, H. (2012b). Cambodia's higher education development in historical perspectives (1863-2012). International Journal of Learning and Development, 2(2), 224-241. 
Rasheed, M. I., Aslam, H. D., \& Sarwar, S. (2010). Motivational issues for teachers in higher education: A critical case of IUB. Journal of Management Research, 2(2), 123.

Rowley, J. (1996). Motivation and academic staff in higher education. Quality Assurance in Education, 4(3): 11-16.

Rue, L. W., \& Byars, L. L. (1983). Management: Theory and application ( $\left.3^{\text {rd }} \mathrm{ed}\right)$. Homewood, Illinois: Richard D. Irwin.

Ryan, R. M., \& Deci, E. L. (2000). Intrinsic and extrinsic motivations: Classic definitions and new directions. Contemporary Educational Psychology, 25(1), 54-67.

Schepers, C., De Gieter, S., Pepermans, R., Du Bois, C., Caers, R., \& Jegers, M. (2005). How are employees of the nonprofit sector motivated? A research need. Nonprofit Management and Leadership, 16(2), 191-208.

Schermerhorn, J. R., Hunt, J. G., \& Osborn, R. N. (1997). Organizational behaviour (6th ed). New York, NY: John Wiley \& Sons, Inc.

Scott, C., Cox S., and Dinham, S. (1999). The occupational motivation, satisfaction and health of English school teachers. Educational Psychology, 19(3), 287-308.

Sederberg, C., Cox, T., \& Clark, S. M. (1990). Motivation and organizational incentives for high vitality teachers: A qualitative perspective. Journal of Research and Development in Education, 24(1), 6-13.

Sekaran, U., \& Bougie, R. (2010). Research methods for business: A skill building approach (5th ed.). New Jersey: John Wiley \& Sons.

Sharabyan, S. K. (2011). An investigation into Iranian language teachers' motivation with respect to their job satisfaction and second language pedagogy. Procedia-Social and Behavioural Sciences, 30, 1071-1075.

Spear, M., Gould, K., \& Lee, B. (2000). Who would be a teacher? : A review of factors motivating and demotivating prospective and practicing teachers. Slough, UK: NFER.

Ssesanga, K., \& Garrett, R. M. (2005). Job satisfaction of university academics: Perspectives from Uganda. Higher Education, 50(1), 33-56. 
Steers, R. M. \& Porter, L. W. (1991). Motivation and work behaviour. New York: McGraw Hill.

Steers, R. M., Mowday, R. T., \& Shapiro, D. L. (2004). The future of work motivation theory. Academy of Management Journal 29(3), 379-387.

Stembridge, A. F. (1990). Teacher motivation: An essential requirement in the integration of faith and learning in Seventh-day Adventist Colleges. Christ in the Classroom, 4, 169-189.

Steyn, G. M. (2002). A theoretical analysis of educator motivation and morale. Retrieved November 28, 2012 from http://uir.unisa.ac.za/handle/10500/237

Umur, E. (2011). A study on motivation and job satisfaction of language teachers at the European university of Lefke, English preparatory school (Unpublished master's thesis). Graduate School of Educational Science, Turkey.

UNESCO. (2006). Higher Education in South-East Asia. Bangkok, Thailand: The UNESCO Asia and Pacific Regional Bureau for Education.

Uy, V. (2012). Factors causing teachers to choose teaching career and remain teaching at one high school in Kandal province (Unpublished Master dissertation). Royal University of Phnom Penh, Cambodia.

Visser-Wijnveen, G. J., Stes, A., \& Van Petegem, P. (2012). Development and validation of a questionnaire measuring teachers' motivations for teaching in higher education. Higher Education, 63(1), 1-16.

Vroom, V. H. (1964). Work and motivation. New York: Wiley Publishing.

Westerman, J., \& Donoghue, P. (1989). Managing the human resource. London: Prentice Hall Professional Technical Reference.

Winter, R., \& Sarros, J. (2002). The academic work environment in Australian universities: A motivating place to work? Higher Education Research and Development, 21(3), 241-258.

World Bank. (2011). Higher education quality and capacity improvement project, Report No: ISR2317 (pp. 1-6). Phnom Penh: The World Bank.

Yan, H. (2009). Student and teacher demotivation in SLA. Asian Social Science January: 110-115. 
Yin, R. K. (2003). Case study research: Design and method ( $3^{\text {rd }}$ ed). Thousand Oaks, CA: Sage.

Yin, R. K. (2012). Applications of case study research $\left(3^{\text {rd }} e d\right)$. Washington DC: Sage Publications, Inc.

Yu, W. H. (1994). A Study of the motivation of teaching staff in the Hong Kong Polytechnic. (Unpublished Doctoral dissertation). University of Hong Kong: Hong Kong. 


\section{Appendices}

\section{Appendix A: Letter to request for university permission}

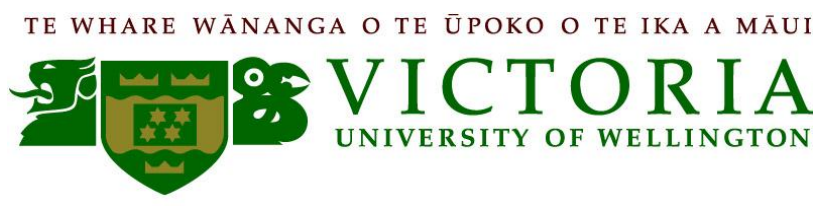

Dear Rector,

I would like to request for permission to conduct a research project in this particular university. I am currently undertaking my Masters Degree in Education in Victoria University of Wellington, New Zealand. The purpose of the research is to investigate the factors that motivate and de-motivate tertiary educators in their teaching careers. I hope the research will make a valuable contribution by providing insights about what factors motivate and de-motivate tertiary educators in their teaching careers. I hope also that the results of this study may serve as a guide for improving tertiary educators' productivity and performance through motivation.

In this research project, I would like to ask for the participation of teachers from two departments to voluntarily complete questionnaire and indicate their willingness to participate in interviews. The questionnaire is anonymous. Completion of each questionnaire will take approximately 15-20 minutes. From those who indicate that they are willing to be interviewed four teachers will be selected for interview on the grounds of their gender and length of experience. The interview will take approximately an hour.

Throughout this project, the participants' identities, departments and university will be kept confidential and pseudonyms will be used. All Participants will be fully informed about research procedures, and consents will be obtained before data collection takes place. A summary of the research findings will be made available for interested participants upon request after the completion of the thesis. The thesis will be submitted to the School of Education Policy and Implementation, Faculty of Education, University of Wellington.

This project has been approved by the Faculty of Education Ethics Committee, Victoria University of Wellington (Reference number: 19148). 
If you have any questions or would like to receive further information regarding the research, you can address it either to me, my supervisors or to the chair of the Victoria University of Wellington Human Ethics Committee. The contact details are provided below.

Yours sincerely,

Dinath Kim

dinathkim@yahoo.com

Dr. Dayle Anderson

Supervisor

dayle.anderson@vuw.ac.nz

Allison Kirkman

Chair of the Victoria University of Wellington Human Ethics Committee

$\underline{\text { Allison.Kirkman@vuw.ac.nz }}$ 


\section{Appendix B: Questionnaire}

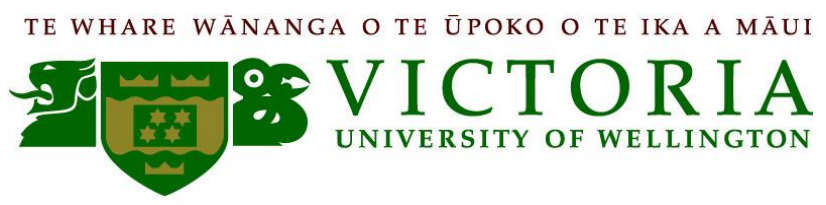

Tertiary teachers' motivation for choosing and remaining in teaching in a public university in Cambodia

\section{Questionnaire}

All information collected through this questionnaire will be anonymous and used for research purposes only. I would appreciate your honest views. Thank you very much.

\section{Part I: Biographical Data}

1. Gender: $\square$ Male $\quad \square$ Female

2. Age: $\square$ 20-29 $\square$ 30-39 $\square$ 40-49 $\square 50$ and over

3. Total number of years in teaching profession: .............years

4. Highest academic degree held:
Bachelors
$\square$ Masters
$\mathrm{PhD}$
Other (specify):

Part II: Please circle the number that comes closest to reflecting your opinion related to teaching at the university level

$1=$ strongly disagree; $2=$ disagree; $\quad 3=$ agree; $\quad 4=$ strongly agree

\begin{tabular}{|l|l|rlll|}
\hline$\underline{N o}$ & $\underline{\text { Statements }}$ & & & \\
\hline 1 & $\begin{array}{l}\text { My choice for becoming a teacher was influenced by my } \\
\text { parents or my previous teachers.. }\end{array}$ & 1 & 2 & 3 & 4 \\
\hline 2 & $\begin{array}{l}\text { My choice for becoming a teacher was influenced by someone } \\
\text { else or other factors. Who or what factor? (Please specify) } \\
\ldots \ldots \ldots \ldots \ldots \ldots \ldots \ldots\end{array}$ & 1 & 2 & 3 & 4 \\
\hline 3 & Teaching was always what I wanted to do. & 1 & 2 & 3 & 4 \\
\hline 4 & I enjoy teaching. & 1 & 2 & 3 & 4 \\
\hline 5 & The teaching profession has a high social value. & 1 & 2 & 3 & 4 \\
\hline 6 & I enjoy working with students. & 1 & 2 & 3 & 4 \\
\hline 7 & $\begin{array}{l}\text { I will be able to help younger people and to bring about change } \\
\text { to education. }\end{array}$ & 1 & 2 & 3 & 4 \\
\hline 8 & I try my best in my teaching duties and being a good teacher. & 1 & 2 & 3 & 4 \\
\hline 9 & I like the people I work with. & 1 & 2 & 3 & 4 \\
\hline 10 & I like my department leaders. & 1 & 2 & 3 & 4 \\
\hline 11 & I like my university leaders. & 1 & 2 & 3 & 4 \\
\hline 12 & I am involved in decision making in my department. & 1 & 2 & 3 & 4 \\
\hline 13 & I am involved in decision making in my university. & 1 & 2 & 3 & 4 \\
\hline 14 & I feel that my ideas are welcomed by the department's & 1 & 2 & 3 & 4 \\
\hline
\end{tabular}




\begin{tabular}{|c|c|c|}
\hline & management. & \\
\hline 15 & $\begin{array}{l}\text { I feel that my ideas are welcomed by the university's } \\
\text { management. }\end{array}$ & $\begin{array}{llll}1 & 2 & 3 & 4\end{array}$ \\
\hline 16 & I often receive feedback on my teaching performance. & 123 \\
\hline 17 & $\begin{array}{l}\text { The feedback is useful and helpful for my teaching } \\
\text { performance. }\end{array}$ & 123 \\
\hline 18 & $\begin{array}{l}\text { I am recognized for my achievements and accomplishments at } \\
\text { the university. }\end{array}$ & $123 \quad 3 \quad 4$ \\
\hline 19 & I feel my efforts are rewarded the way they should be. & 123 \\
\hline 20 & I feel I am being paid a fair amount for the work I do. & 123 \\
\hline 21 & I receive support from my department and the university. & 123 \\
\hline 22 & I have a lot of workload in my teaching. & 123 \\
\hline 23 & I am encouraged to undertake research at this university. & 123 \\
\hline 24 & $\begin{array}{l}\text { I am encouraged and provided opportunities for upgrading } \\
\text { knowledge and skills. }\end{array}$ & 123 \\
\hline 25 & $\begin{array}{l}\text { I am empowered to choose and implement my own way of } \\
\text { teaching practices. }\end{array}$ & 123 \\
\hline 26 & I have sufficient teaching resources to support my teaching. & 123 \\
\hline 27 & There is really little chance for promotion on my job. & 123 \\
\hline 28 & $\begin{array}{l}\text { Teachers who work hard have fair opportunities to get } \\
\text { promoted. }\end{array}$ & 123 \\
\hline 29 & $\begin{array}{l}\text { Teachers are treated fairly regardless of groups, age, gender... } \\
\text { etc. }\end{array}$ & $\begin{array}{llll}1 & 2 & 3 & 4\end{array}$ \\
\hline 30 & $\begin{array}{l}\text { This university provides sufficient technology to support my } \\
\text { teaching. }\end{array}$ & 123 \\
\hline 31 & Students at this university are qualified and well-disciplined. & 123 \\
\hline 32 & $\begin{array}{l}\text { I intend to remain in the teaching profession for the rest of my } \\
\text { working life. }\end{array}$ & $\begin{array}{llll}1 & 2 & 3 & 4\end{array}$ \\
\hline
\end{tabular}


Part III: Below are a variety of factors that may affect your motivation.

In Column A, circle the number that best reflects the degree to which each factor motivates you in general as a teacher (i.e. not specifically at this university).

In Column B, circle the number that best reflects your level of satisfaction (i.e. degree of motivation) related to each factor at this university.

1 = highly de-motivating; $\quad 2=$ de-motivating; $\quad 3=$ motivating; $\quad 4=$ highly motivating

\begin{tabular}{|c|c|c|c|}
\hline No & Factors & $\begin{array}{l}\text { Column A: } \\
\text { Importance in } \\
\text { general }\end{array}$ & $\begin{array}{l}\text { Column B: } \\
\text { Satisfaction } \\
\text { at this } \\
\text { university }\end{array}$ \\
\hline 1 & Remuneration (salary) & 1234 & 1234 \\
\hline 2 & Opportunities for scholarships for further studies & 1234 & 1234 \\
\hline 3 & Opportunities for undertaking research & 1234 & $123 \quad 4$ \\
\hline 4 & Opportunities for upgrading knowledge and skills & 1234 & 1234 \\
\hline 5 & Opportunities for promotion & 1234 & 1234 \\
\hline 6 & Recognition and rewards & 1234 & 1234 \\
\hline 7 & Social status of teaching profession & 1234 & 1234 \\
\hline 8 & Helping younger people & 1234 & 1234 \\
\hline 9 & Contributing to society & 1234 & 1234 \\
\hline 10 & Management support & 1234 & $\begin{array}{llll}1 & 2 & 3 & 4\end{array}$ \\
\hline 11 & $\begin{array}{l}\text { Involvement in decision making at the departmental } \\
\text { level }\end{array}$ & 1234 & 1234 \\
\hline 12 & Involvement in decision making at the university level & 1234 & 1234 \\
\hline 13 & Feedback from management & 1234 & $\begin{array}{llll}1 & 2 & 3 & 4\end{array}$ \\
\hline 14 & Feedback from students & 1234 & 1234 \\
\hline 15 & $\begin{array}{l}\text { Work environment-facility (e.g. buildings, } \\
\text { classrooms, teachers' rooms, toilets, etc...) }\end{array}$ & 1234 & 1234 \\
\hline 16 & $\begin{array}{l}\text { Work environment-physical (e.g. class size, teaching } \\
\text { materials, etc...) }\end{array}$ & 1234 & $123 \quad 3$ \\
\hline 17 & $\begin{array}{l}\text { Work environment-social (relationship with } \\
\text { colleagues, leaders, students, etc...) }\end{array}$ & 1234 & $\begin{array}{llll}1 & 2 & 3 & 4\end{array}$ \\
\hline
\end{tabular}




\begin{tabular}{|c|c|c|c|c|c|c|c|c|}
\hline 18 & Work load & & 23 & 34 & & 2 & 3 & \\
\hline 19 & $\begin{array}{l}\text { Autonomy in teaching (The ability to control my own } \\
\text { teaching) }\end{array}$ & 1 & 23 & 34 & 1 & 2 & 3 & 4 \\
\hline 20 & Access to use of appropriate, quality technology & & 23 & 34 & 1 & 2 & 3 & 4 \\
\hline 21 & Student outcomes and performance & 1 & 23 & 34 & 1 & 2 & 3 & 4 \\
\hline 22 & Students' respect & 1 & 23 & 34 & 1 & 2 & & 4 \\
\hline 23 & Nepotism & 1 & 23 & 34 & 1 & 2 & 3 & 4 \\
\hline
\end{tabular}

Part IV. Please answer the following questions.

1. What factors influenced you the most in deciding to become a tertiary teacher?

2. What factors would most motivate you to remain in tertiary teaching?

6. Have you ever thought about leaving tertiary teaching? $\quad \square$ Yes $\quad \square$ No why? 
(Please return this questionnaire to the post box provided in your department)Thank you! 


\section{Appendix C: Interview questions}

1. Why did you decide to be a tertiary teacher?

2. Why do you continue to be a tertiary teacher? What factors influence your decision to stay? Why are these factors important?

3. Could you think of a time you felt motivated and enthusiastic in your teaching. Why and what made you feel that way?

4. What currently motivates you to apply your best efforts to your work at the university? Why are these factors important?

5. Are there obstacles or dissatisfactions that discourage you from applying your best effort? What are they? How important are they? Why? How do they impact on what you do?

6. Do you feel that you are receiving any motivational support from the university? What form does this take? How influential is this support to your remaining in your profession?

7. How do you see the contribution your position makes to this university, the students, and Cambodia?

8. Suppose you were given the opportunity to change anything you desire in your current position, what would you change that would motivate you to deliver your most effective level of performance?

9. Have you ever thought about leaving your profession? Why or why not?

10. If you are to think about leaving your teaching profession, what would be the factors that force you to leave? Why? 


\section{Appendix D: Teacher Information Sheet}

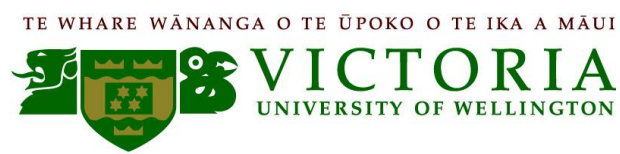

\section{Information Sheet for the Participants}

Dear Teacher,

I am Dinath Kim and doing a Master's degree with the Faculty of Education at Victoria University of Wellington, New Zealand. To complete my thesis, I am now conducting a research project entitled "Tertiary teachers' motivation for choosing and remaining in teaching in a public university in Cambodia". I hope the research will make a valuable contribution by providing insights about what factors motivate and demotivate tertiary educators in their teaching careers. I hope also that the results of this study may serve as a guide for improving tertiary educators' productivity and performance through motivation. I invite you to take part in this research project.

Your participation will involve responding to a questionnaire. Additionally, if you indicate that are willing, you may be selected to participate in an interview.

$>$ Questionnaire: The questionnaire is anonymous. Completion of each questionnaire will take approximately 15-20 minutes.

$>$ Interview: If you volunteer to participate in the interview, you can withdraw up until two weeks after interview without having to explain why and exercise the option of removing your data from the study at that time. You may also refuse to answer any questions you do not want to answer and still remain in the study. The interview will take approximately an hour. The interview would be scheduled at times and places that are convenient for you.

\section{Participant's Rights}

- ask any questions about the study at any time during participation

- provide information on the understanding that you, your department or your university will not identified

- have the opportunity to check and amend your transcript before data analysis commences

- be provided with a summary of findings of this research and access to the thesis

Once collected, questionnaire and interview data will be stored securely in password protected files and a locked cabinet. Myself and my supervisor will only have access to all the data. The data will be deleted after the completion of my thesis. 
This research has been assessed and approved by the Victoria University of Wellington Faculty of Education Ethics Committee (Reference number: 19148). If you have any questions about the way research is being conducted, please feel free to contact either me, my supervisor, or the chair of the Victoria University of Wellington Human Ethics Committee.

Yours sincerely,

\section{Dinath Kim}

(Phone: 012 566625)

Dr. Dayle Anderson

Supervisor

dayle.anderson@vuw.ac.nz

Allison Kirkman

Chair of the Victoria University of Wellington Human Ethics Committee Allison.Kirkman@vuw.ac.nz 


\section{Appendix E: Teacher Consent Form}

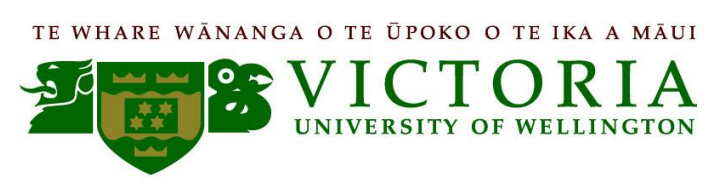

\section{Teacher Consent Form}

Title of Research Study: Tertiary teachers' motivation for choosing and remaining in teaching in a public university in Cambodia

This research has been assessed and approved by the Victoria University of Wellington Faculty of Education Ethics Committee (Reference number: 19148).

\begin{tabular}{|l|l|}
\hline & $\begin{array}{l}\text { Please tick if } \\
\text { agree }\end{array}$ \\
\hline I have had the purpose of the research project discussed with me. & \\
\hline $\begin{array}{l}\text { I confirm that I have read and understand the information sheet for the } \\
\text { above study. }\end{array}$ & \\
\hline $\begin{array}{l}\text { I have had the opportunity to consider the information, ask questions and } \\
\text { have had these answered satisfactorily. }\end{array}$ & \\
\hline $\begin{array}{l}\text { I understand that my participation is voluntary and that I am free to } \\
\text { withdraw from this research study up until } 2 \text { weeks after interview, } \\
\text { without giving any reason. }\end{array}$ & \\
\hline $\begin{array}{l}\text { I understand that my name, department and university will be kept } \\
\text { confidential and not used in any publications. }\end{array}$ & \\
\hline $\begin{array}{l}\text { I understand that my responses would be stored safely and destroyed after } \\
\text { completion of the thesis writing. }\end{array}$ & \\
\hline $\begin{array}{l}\text { I understand that I have the opportunity to check and amend my transcript } \\
\text { before data analysis commences. }\end{array}$ & \\
\hline $\begin{array}{l}\text { I understand that I have the right to ask any questions about the study at } \\
\text { any time during participation. }\end{array}$ & \\
\hline $\begin{array}{l}\text { I have the right to be provided with a summary of findings of this research } \\
\text { and access to the thesis. }\end{array}$ & \\
\hline I agree to take part in the above research study. & \\
\hline
\end{tabular}

I would like a copy of the results (Please put a tick in this box if you would like a copy)

Name:

Signature:

Date: 


\section{Appendix F: Interview participation form}

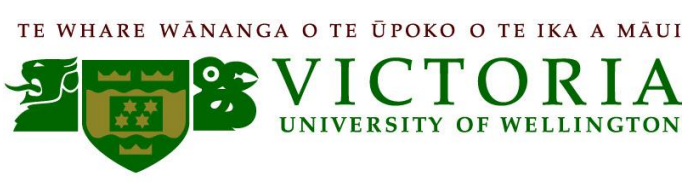

Interview Participation Form

Who would like to participate in the interview?

If you are interested in participate in the interview, please fill in the information below. The interview will be up to one hour at your convenience place and time.

- Gender: $\square$ Male $\quad \square$ Female

- Number of years teaching at the university: years

- Department:

- Contact email:

Phone:

Name :

Signature:

(Please return this form to the post box provided in your department) 


\section{Appendix G: Pilot participant information sheet}

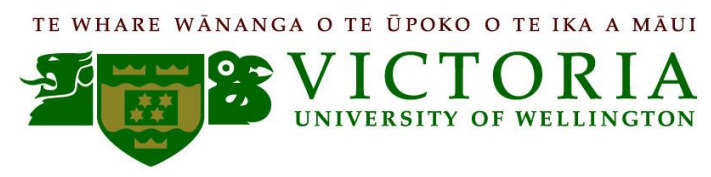

\section{Information Sheet for Participants (Pilot)}

Dear Teacher,

I am Dinath Kim and doing a Master's degree with the Faculty of Education at Victoria University of Wellington, New Zealand. To complete my thesis, I am now conducting a research project entitled "Tertiary teachers' motivation for choosing and remaining in teaching in a public university in Cambodia". I hope the research will make a valuable contribution by providing insights about what factors motivate and de-motivate tertiary educators in their teaching careers. I hope also that the results of this study may serve as a guide for improving tertiary educators' productivity and performance through motivation. I invite you to take part in this pilot research project.

Your participation in this pilot study involves responding to a questionnaire. Additionally, if you indicate that are willing, you may participate in an interview.

$>$ Questionnaire: The questionnaire is anonymous. Completion of each questionnaire will take approximately 15-20 minutes. If you fill in the questionnaire, it does not mean you will have to participate in the interview.

Interview: If you volunteer to participate in the interview, you can withdraw at any time without having to explain why. You may also refuse to answer any questions you do not want to answer. The interview will take approximately an hour. The interview would be scheduled at times and places that are convenient for you. If you volunteer to participate in the interview, please contact me by email or phone provided below.

\section{Pilot Participant's Rights}

You are under no obligation to accept this invitation. If you participate, you have the right to:

- decline to contribute to the above questionnaire

- ask any questions about the study at any time during participation

- provide information on the understanding that you, your department or your university will not identified

Data gathered during the pilot will not be reported in the final study. This stage is purely to identify any problems with the way I am collecting information. Any material collected will be kept confidential and destroyed after analysis. 
This research has been approved by the Victoria University of Wellington Faculty of Education Ethics Committee (Reference number: 19148). If you have any questions about the way research is being conducted, please feel free to contact either me, my supervisor, or the chair of the Victoria University of Wellington Human Ethics Committee.

Dinath Kim

dinathkim@yahoo.com (Phone: 012566625)

Dr. Dayle Anderson

Supervisor

Dayle.anderson@vuw.ac.nz

Allison Kirkman

Chair of the Victoria University of Wellington Human Ethics Committee

Allison.Kirkman@vuw.ac.nz 


\section{Appendix H: Pilot participant consent form}

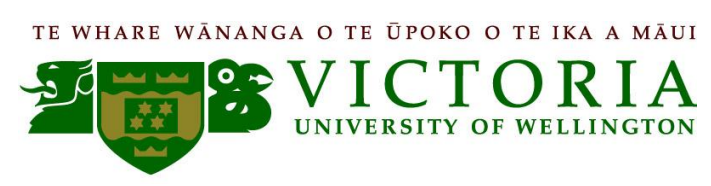

\section{Teacher Consent Form (Pilot)}

Title of Research Study: Tertiary teachers' motivation for choosing and remaining in teaching in a public university in Cambodia

This research has been approved by the VUW Faculty of Education Ethics Committee (Reference number: 19148).

\begin{tabular}{|l|l|}
\hline & $\begin{array}{l}\text { Please tick if } \\
\text { agree }\end{array}$ \\
\hline I have had the purpose of the research project discussed with me. & \\
\hline $\begin{array}{l}\text { I confirm that I have read and understand the information sheet for the } \\
\text { above study. }\end{array}$ & \\
\hline $\begin{array}{l}\text { I have had the opportunity to consider the information, ask questions and } \\
\text { have had these answered satisfactorily. }\end{array}$ & \\
\hline $\begin{array}{l}\text { I understand that my participation is voluntary and that I am free to } \\
\text { withdraw at any time, without giving any reason. }\end{array}$ & \\
\hline I understand that my name, department and university will not be used. & \\
\hline I understand that my responses will not be reported as part of the study. & \\
\hline $\begin{array}{l}\text { I understand that I have the right to ask any questions about the study at } \\
\text { any time during participation. }\end{array}$ & \\
\hline I agree to take part in the pilot for this research study. & \\
\hline
\end{tabular}

Name:

Signature:

Date: 


\title{
Appendix I: Transcriber's confidentiality agreement
}

\author{
TRANSCRIBER'S CONFIDENTIALITY AGREEMENT \\ Teacher Motivation Research Project
}

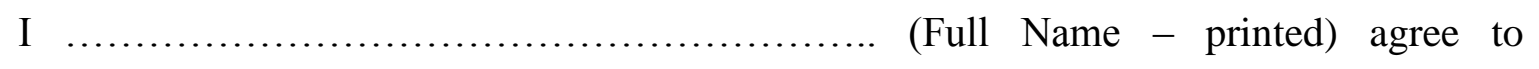
transcribe the electronic sound files provided to me.

I agree to keep confidential all the information provided to me and to ensure safe storage of files and transcripts while in my care.

I will not make any copies of the transcripts or keep any record of them, other than those required for the project.

Signature:

Date:

Dinath Kim

dinathkim@yahoo.com

Dr. Dayle Anderson

dayle.anderson@vuw.ac.nz 